\title{
Regular prices and sales
}

\author{
Paul Heidhues \\ European School of Management and Technology \\ Botond KőszegI \\ Department of Economics, Central European University
}

\begin{abstract}
It is widely known that loss aversion leads individuals to dislike risk and, as has been argued by many researchers, in many instances this creates an incentive for firms to shield consumers and employees against economic risks. Complementing previous research, we show that consumer loss aversion can also have the opposite effect: it can lead a firm to optimally introduce risk into an otherwise deterministic environment. We consider a profit-maximizing monopolist selling to a loss-averse consumer, where (following Köszegi and Rabin 2006) we assume that the consumer's reference point is her recent rational expectations about the purchase. We establish that for any degree of consumer loss aversion, the monopolist's optimal price distribution consists of low and variable "sale" prices and a high and atomic "regular" price. Realizing that she will buy at the sales prices and hence that she will purchase with positive probability, the consumer chooses to avoid the painful uncertainty in whether she will get the product by buying also at the regular price. This pricing pattern is consistent with several recently documented facts regarding retailer pricing. We show that market power is crucial for this result: when firms compete ex ante for consumers, they choose deterministic prices.
\end{abstract}

Keywords. Reference-dependent utility, gain-loss utility, loss aversion, sales, supermarket pricing, sticky prices.

JEL CLASSIFICATION. D03, D42, D81, L13.

Paul Heidhues: paul . heidhues@esmt . org

Botond Kőszegi: botond@econ . berkeley . edu

We are extremely grateful to Rani Spiegler for working out the variant of our model with no loss aversion in money (Section 4.1), and for convincing us to include it. Takeshi Murooka provided excellent research assistance. We also thank Stefano DellaVigna, Erik Eyster, Yoram Halevy, Ulrich Kamecke, Emir Kamenica, Matthew Rabin, Andrei Shleifer, and Joel Sobel for enlightening discussions, and seminar and conference audiences for comments. Heidhues gratefully acknowledges Berkeley's hospitality while the first draft of this paper was written and financial support from the Deutsche Forschungsgemeinschaft through SFB/TR15. Kőszegi thanks the Central Bank of Hungary for hospitality while some of this work was completed and the National Science Foundation for financial support under Award 0648659. Heidhues and Kőszegi thank the European Research Council for support under Starting Grant 313341.

Copyright $\odot 2014$ Paul Heidhues and Botond Kőszegi. Licensed under the Creative Commons AttributionNonCommercial License 3.0. Available at http: //econtheory . org.

DOI: 10.3982/TE1274 


\section{INTRODUCTION}

It is widely understood in the literature that loss aversion-whereby individuals dislike losses relative to a reference point more than they like same-sized gains-leads individuals to be very averse to small- and modest-scale monetary risk, and some researchers believe that loss aversion is the primary explanation for aversion to such risk. ${ }^{1}$ Many existing theories exploit this basic implication of loss aversion to show that firms often have an incentive to shield loss-averse consumers or employees from uncertainty in the environment. ${ }^{2}$ As a complement to previous work, in this paper we identify an economically central setting in which the opposite is the case: a firm selling to lossaverse consumers optimally introduces random "sales" into an otherwise riskless environment. The resulting distribution of prices is not only a theoretically novel implication of loss aversion, but it is consistent with some empirically documented patterns in retailer pricing summarized in Section 2. While we are unaware of compelling evidence on the importance of our mechanism relative to those in other models of sales, our theory seems to be a promising explanation to consider for at least two reasons. First, it is based on loss aversion, one of the most well documented phenomena in human behavior. Second, as demonstrated by the combination of previous work and ours, unlike most theories loss aversion is consistent with the puzzling combination of flexibility in observed consumer prices (reflected in frequent sales) and stickiness in observed consumer prices (reflected in the stickiness of the regular price). Furthermore, our theory makes additional predictions on the circumstances under which random sales are likely to be observed.

We assume that a risk-neutral profit-maximizing monopolist sells a single product to a representative consumer with known valuation and that the consumer's reference point for evaluating her purchase is her recent rational expectations about the purchase. The monopolist announces a price distribution, and the consumer forms her expectations after observing the price distribution. Then, a price is drawn from the distribution and the consumer decides whether to buy a single item of the good. Our main result establishes that the optimal price distribution consists of low and variable "sale" prices and a high and atomic "regular" price. The sale prices are chosen such that it is not

\footnotetext{
${ }^{1}$ For instance, Rabin (2000b) and Rabin and Thaler (2001) show that in an expected-utility-over-wealth model, nontrivial aversion to modest-scale risk must be associated with implausible and empirically unobserved extreme aversion to large-scale risk, so that expected utility over wealth cannot explain attitudes toward both modest-scale and large-scale risks. They argue that loss aversion is likely a better explanation for aversion to small- and modest-scale risks. Benartzi and Thaler (1995) and Barberis et al. (2001) demonstrate that investor loss aversion can help explain the equity premium puzzle. Sydnor (2010) documents that homeowners display extreme aversion to risk in their deductible choices for homeowners' insurance and argues that loss aversion can contribute to explaining this behavior.

${ }^{2}$ For instance, Sibly (2002) shows that consumer loss aversion can generate "price stickiness"-the unresponsiveness of prices to changes in cost or demand circumstances-while Heidhues and Köszegi (2008) establish that it can also explain why nonidentical competitors often sell differentiated goods at identical prices. Similarly, Herweg and Mierendorff (2013) argue that the prevalence of flat-rate contracts can be due to consumer loss aversion. In models of moral hazard with loss-averse agents, Herweg et al. (2010) and Macera (2012) demonstrate that the optimal incentive contract features less variation in the wage than would be expected based on classical models.
} 
credible for the consumer not to buy at these prices. Then, because the consumer expects to purchase with positive probability and dislikes uncertainty of whether she will get the product, she chooses to buy also at the regular price. Furthermore, because the consumer dislikes uncertainty in how much she pays, to get her to choose to buy at the regular price the monopolist makes the regular price sticky. We also show that market power is necessary for random pricing to be optimal: if two firms compete ex ante for consumers by announcing their price distributions, they choose deterministic prices in equilibrium.

Section 3 presents our basic model, which uses the framework of Köszegi and Rabin (2006) to incorporate consumer loss aversion into a simple model of first-degree price discrimination. There is a single product and a single representative consumer. If the consumer gets the product, she derives consumption utility $v$ from it and she also derives additive consumption disutility from any money she pays. In addition, the consumer derives gain-loss utility from the comparison of her consumption utility in the product and money dimensions to a reference point equal to her lagged expectations regarding the same outcomes, with losses being more painful than equal-sized gains are pleasant. Suppose, for example, that the consumer had been expecting to buy the product for either $\$ 5$ or $\$ 7$. If she buys it for $\$ 6$, she experiences no gain or loss in the product dimension and "mixed feelings" in the money dimension consisting of a loss relative to the possibility of paying $\$ 5$ and a gain relative to the possibility of paying $\$ 7$, with the weight on the loss equal to the probability with which she had been expecting to pay $\$ 5$. If she does not buy, she experiences a loss in the product dimension and (paying \$0) a gain in the money dimension relative to both prices $\$ 5$ and $\$ 7$. To determine expectations and behavior with these preferences, we assume that the consumer must form credible purchase plans: given the expectations induced by her plan of which prices to buy at, buying at exactly those prices must be optimal. Among credible plans, the consumer chooses one that maximizes her ex ante expected utility, which we call a preferred personal equilibrium.

The above consumer interacts with a risk-neutral profit-maximizing monopolist with deterministic production cost. In period 0 , the monopolist commits to a price distribution. This commitment assumption captures, in a reduced form, the idea that a patient firm has the incentive to develop a reputation for playing the long-run optimal price distribution. The consumer observes the price distribution while forming expectations about her own price-contingent behavior. In period 1, a price is drawn from the distribution, and the consumer decides whether to buy a single item of the good. For technical reasons, we assume that the price distribution must be discrete with atoms at least $\Delta>0$ apart, and look for the limit-optimal price distribution as $\Delta$ approaches zero.

We analyze our basic model in Section 4. We show that for any loss-averse preferences by the consumer, the monopolist's limit-optimal price distribution looks qualitatively like that illustrated in Figure 1: it consists of a region of continuously distributed low sale prices and a single atomic high regular price. We explain the intuition in three parts. 


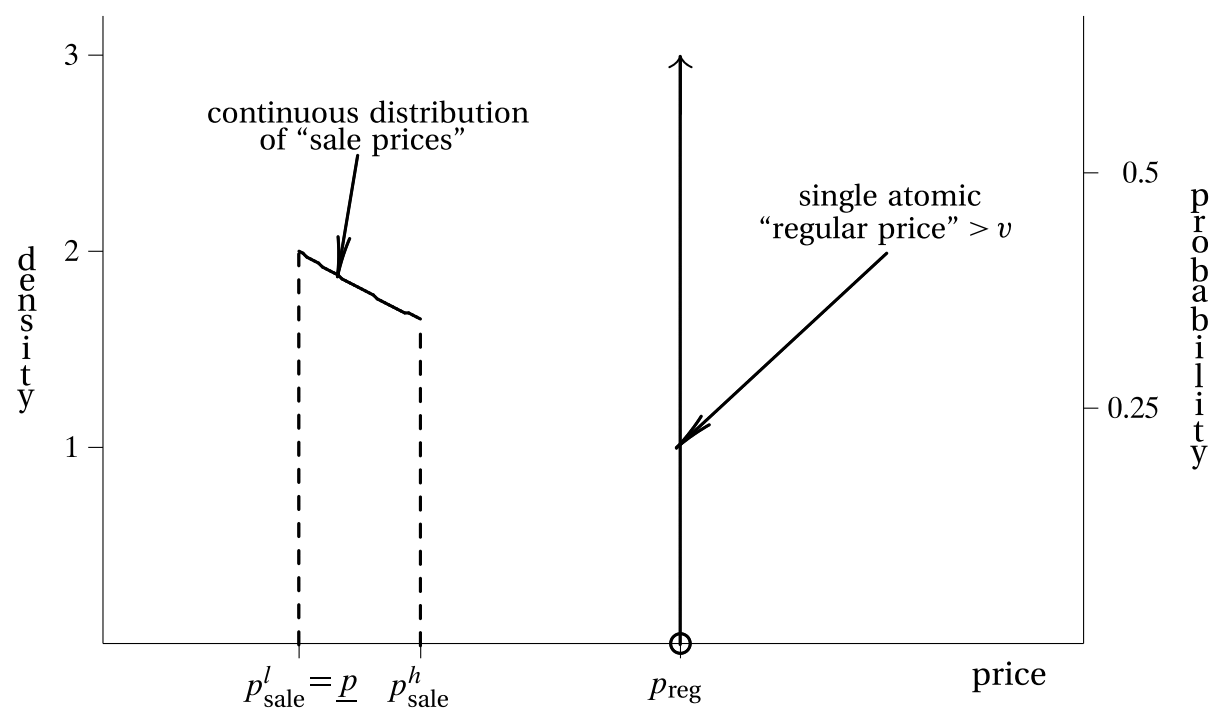

Figure 1. A limit-optimal price distribution. Graph of the limit-optimal price distribution when the monopolist sells to a single consumer with known consumption value $v$ for the product. To be consistent with experimental evidence suggesting two-to-one loss aversion, loss-aversion parameters are $\lambda=3$ and $\eta=1$ (see Section 3 for a definition of these variables). The left axis shows the scale for the density of the sale prices and the right axis shows the scale for the probability of the regular price atom. In this example, $p_{\text {sale }}^{l}=0.5 \cdot v, p_{\text {sale }}^{h} \approx 0.81 \cdot v$, and $p_{\text {reg }} \approx 1.47 \cdot v$. Although the location of the prices and the weight placed on the regular price are typically different, the limit-optimal price distribution has the same qualitative features (a region of continuously distributed low prices and an atomic high price) for any $\lambda>1$ and $\eta>0$.

First, despite a loss-averse consumer's dislike of uncertainty-in fact, by exploiting this dislike-the monopolist can earn greater profits by charging uncertain prices than by charging a deterministic price. If the monopolist uses a deterministic price $p$, then it cannot earn revenue of more than $v .^{3}$ But consider instead the strategy of sometimes charging sale prices low enough to make not buying at these prices noncredible and at other times charging a high regular price. The consumer's realization that she will buy at the sale prices engages an expectations-based variant of the endowment effect first discussed by Thaler (1980) and documented, for instance, by Kahneman et al. (1990): if she plans not to buy at the high regular price, she expects to get the product with an interior probability, so she feels an unpleasant loss if she does not get it. To avoid this sense of loss, she prefers to eliminate uncertainty in whether she will get the product and is, therefore, willing to buy at a regular price that exceeds $v$ somewhat. As with the endowment effect, the two-dimensional nature of loss aversion is crucial for this logic to hold: if the consumer experienced gain-loss utility over her total consumption utility

\footnotetext{
${ }^{3}$ In this case, any rational expectations match actual behavior, so in PPE, gain-loss utility must be zero. As a result, the consumer prefers to maximize consumption utility, not buying if $p>v$. And such a plan is credible: once the consumer makes her preferred plan not to buy, she would experience paying for the product as a painful loss, so that she would especially not like to buy.
} 
rather than over the product and money dimensions separately, buying at a regular price that exceeds $v$ would neither be optimal ex post nor reduce risk ex ante.

Going further, by exploiting a type of time inconsistency to push the consumer's expected utility below zero, the firm can lead her to pay not only a regular price that exceeds $v$, but also an average price that exceeds $v$. When the consumer decides to buy at a sale price in period 1 , she does not take into account that this increases her period- 0 expectations to consume and spend money, lowering her expected utility. In this sense of leading the consumer to choose outcomes she does not like ex ante, the monopolist's pricing strategy is manipulative.

Second, the profit-maximizing way to execute the above "luring sales" is to put a small weight on each of a large number of sale prices. If the consumer had expected not to buy, she would experience paying for the product as a loss and getting the product merely as a gain, creating a low willingness to pay for the product. To make not buying noncredible then, the monopolist puts a small weight on a low price $p$ chosen such that even if the consumer expected not to buy, she would buy at $p$. Since the consumer realizes that she will buy at $\underline{p}$, she experiences not getting the product partially as a loss rather than a foregone gain and paying for it partially as a foregone gain rather than a loss, increasing her willingness to pay. As a result, not buying at a slightly higher price is also noncredible, allowing the monopolist to charge higher prices at all other times. Continuing this logic further, the monopolist needs to charge each sale price with only a low probability.

Third, because the role of the regular price is completely different from that of sale prices, the monopolist chooses that price to be atomic. The regular price is chosen by the monopolist not to make a strategy of never buying noncredible, but to ensure that the consumer is willing to buy at all prices rather than just at the sale prices. Hence, there is no reason to make the regular price random: the monopolist just sets it at the consumer's endogenous willingness to pay for the product.

In Section 5, we turn to various extensions and modifications of our framework, making several predictions on when random sales are less likely to be observed. In Section 5.1, we consider perfect ex ante competition for consumers: two firms simultaneously announce their price distributions in period 0 , and in the same period the consumer decides which firm to visit in period 1. Because a price distribution that manipulates the consumer into suboptimal behavior would not attract her, in this case, firms offer deterministic prices. This result shows that some market power is necessary for random pricing to obtain in equilibrium. In Section 5.2, we argue that-although the main point of this paper is to demonstrate the optimality of random prices-in a sense our paper does not contradict previous results that loss aversion leads to reduced price variation. In particular, our results are consistent with stickiness in the regular price and with price stickiness in a competitive environment. Intuitively, if the regular price was uncertain, the consumer would experience a gain if it turned out relatively low and a loss if it turned out relatively high. Due to loss aversion, she would feel the loss more heavily, making her less willing to buy at an uncertain regular price. Hence, not only does a monopolist not need variation in the regular price (as we explained above), it has an incentive to keep the regular price sticky to induce the consumer to buy at the regular 
price in addition to the sale prices. Similarly, because a consumer dislikes uncertainty in the price, to attract her from a competitor a firm has an incentive to eliminate variation in the price, leading to sticky prices under ex ante competition. Finally, in Section 5.3, we show that if it is sufficiently costly for consumers to observe the realized price before buying, then the monopolist chooses a deterministic price.

In Section 6, we summarize the behavioral economics and pricing literature most related to our paper. We conclude the paper in Section 7 by pointing out some pricing patterns that our model cannot explain. All proofs are provided in the Appendix.

\section{EVIDENCE ON PRICING}

The predictions of our model are qualitatively consistent with much of the evidence on supermarket pricing. Supermarket prices change every two or three weeks on average, typically by moving away from the regular price and then quickly returning to it (Chevalier et al. 2003, Kehoe and Midrigan 2008, Eichenbaum et al. 2009). Furthermore, most of these temporary price changes are sales (price decreases rather than increases), with the mean deviation being $-22 \%$ of the regular price (Kehoe and Midrigan 2008).

This price variability occurs despite considerable stickiness in the regular prices, which change about once a year on average (Kehoe and Midrigan 2008, Eichenbaum et al. 2009). In addition, consumer retail prices tend to be sticky more broadly. In a classic study, Cecchetti (1986) finds that the time between magazine price changes is typically over a year and sometimes over a decade. For a selection of goods in a mail-order catalog, Kashyap (1995) observes an average of 14.7 months between price changes. MacDonald and Aaronson (2006) document that for restaurant prices, the median duration between price changes is around 10 months. Even at the lower end of the stickiness spectrum, Bils and Klenow (2004) find a median price duration of 4.3 months for nonshelter items in the Bureau of Labor Statistics (BLS) data underlying the Consumer Price Index.

In a classical reference-independent model, any change in the firm's cost or elasticity of demand creates an incentive to change prices. From this perspective, it is likely that changes in the economic environment are far too rapid to justify the above lags between price changes. As suggestive evidence for this observation, Eichenbaum et al. (2009) document that conditional on the weekly price being constant and equal to the regular price, the standard deviation of quantities sold is $42 \%$.

Recent empirical research also shows that sale prices are less sticky than regular prices. Klenow and Kryvtsov (2008) document that it is more likely for a sale price to change from one promotion to the next than for a regular price to change when interrupted by a sale. Nakamura and Steinsson (2011) find that for the median product category, the sale price changes in $48.7 \%$ of the weeks during a multiweek sale, while the regular price changes in only 6.1 percent of weeks. The number of unique prices as a fraction of total weeks spent on sale is 0.434 , while the same number for regular prices is 0.045 .

It is important to note that the frequency of sales that has been observed at supermarkets does not seem to be a general feature of consumer retail prices: many retailers simply charge a sticky price and rarely have noncyclical sales. Movies, for instance, 
largely sell at the same price for extended periods of time (Einav and Orbach 2007). Similarly, many previous studies of price stickiness, including the Cecchetti (1986) study on newspapers and the MacDonald and Aaronson (2006) study on restaurants mentioned above, do not seem to find frequent sales. And while Eichenbaum et al. (2009) report that sale prices constitute about $30 \%$ of price observations at supermarkets, Klenow and Kryvtsov (2008) find that overall they constitute only $8 \%$ of nonfood price observations. We are unaware of evidence on whether the pattern of sale frequencies across different types of retailers is consistent with our model's predictions that sales are less likely to occur when prices are harder to observe or there is competition.

\section{Model}

In this section, we introduce our basic model of pricing with a loss-averse consumer. A risk-neutral profit-maximizing monopolist is looking to sell a single product with deterministic production cost $c$ to a single representative consumer. We suppose that $c$ is sufficiently low for the monopolist to sell to the consumer; this will be the case whenever the revenue from the price distribution we identify below exceeds $c$. The interaction between the monopolist and the consumer lasts two periods, 0 and 1 . In period 0 , the monopolist commits to a price distribution $\Pi(\cdot)$ for its product. The consumer learns the price distribution, makes a price-contingent purchase plan, and forms stochastic beliefs regarding her consumption outcomes. In period 1 , a price $p$ is drawn from $\Pi(\cdot)$, and after observing the price, the consumer decides whether to buy a single item of the product, choosing quantity $b \in\{0,1\}$. For technical and expositional reasons, we assume that any indifference by the consumer in period 1 is broken in favor of buying.

Our assumption that the firm can commit to the price distribution captures, in a static reduced form, a patient firm's dynamic incentives to forego possible short-term profits to manage consumers' price expectations. One possible microfoundation for this assumption is a model in which (based on Fudenberg and Levine 1989) the firm can develop a "reputation" for playing the optimal committed price distribution. More generally, it seems plausible to assume that over time consumers learn a firm's basic pricing strategy and incorporate it into their expectations, and that firms take this into account. This assumption is clearly crucial for our main result: once the consumer has formed expectations, the firm would prefer not to charge sale prices, so commitment is necessary for it to use sales as a way to induce an expectation to buy in the consumer.

Our model of consumer behavior follows the approaches of Konszegi and Rabin (2006) and Heidhues and Köszegi (2008), but it adapts and simplifies these theories to fit the decision of whether to purchase a single product. The consumer's utility function has two components. Her consumption utility is $(v-p) b$, so that the consumption value of the product is $v$. Consumption utility can be thought of as the classical notion of outcome-based utility. In addition, the consumer derives gain-loss utility from the comparison of her period-1 consumption outcomes to a reference point given by her period-0 expectations (probabilistic beliefs) about those outcomes. Let $k^{v}=v b$ and $k^{p}=-p b$ be the consumption utilities in the product and money dimensions, respectively. For any riskless consumption-utility outcome $k^{i}$ and riskless reference point $r^{i}$ in 
dimension $i$, we define total utility in dimension $i$ as $u\left(k^{i} \mid r^{i}\right)=k^{i}+\mu\left(k^{i}-r^{i}\right)$. Hence, for any $\left(k^{v}, k^{p}\right)$ and $\left(r^{v}, r^{p}\right)$, total utility is

$$
u\left(k^{v} \mid r^{v}\right)+u\left(k^{p} \mid r^{p}\right)=k^{v}+\mu\left(k^{v}-r^{v}\right)+k^{p}+\mu\left(k^{p}-r^{p}\right) .
$$

We assume that $\mu$ is two-piece linear with a slope of $\eta>0$ for gains and a slope of $\eta \lambda>\eta$ for losses. By positing a constant marginal utility from gains and a constant and larger marginal disutility from losses, this formulation captures prospect theory's (Kahneman and Tversky 1979, Tversky and Kahneman 1991) loss aversion, but ignores prospect theory's diminishing sensitivity. The parameter $\eta$ can be interpreted as the weight attached to gain-loss utility and $\lambda$ can be interpreted as the coefficient of loss aversion. ${ }^{4}$

Beyond loss aversion, our specification in (1) incorporates the assumption that the consumer assesses gains and losses in the two dimensions- the product and moneyseparately. Hence, if her reference point is not to get the product and not to pay anything, for instance, she evaluates getting the product and paying for it as a gain in the product dimension and a loss in the money dimension, and not as a single gain or loss depending on total consumption utility relative to the reference point. This is consistent with much experimental evidence commonly interpreted in terms of loss aversion. ${ }^{5}$ It is also crucial for our results: if gain-loss utility was defined over total consumption utility - as would be the case, for example, in an experiment with induced values-then for any reference point, the consumer's willingness to pay for the product would be $v$, so that the firm would set a deterministic price equal to $v$. We will discuss how gain-loss utility and loss aversion in each of the two dimensions contributes to our results.

Since we assume below that expectations are rational, and in many situations such rational expectations are stochastic, we extend the utility function in (1) to allow for the reference point to be a pair of probability distributions $F=\left(F^{v}, F^{p}\right)$ over the two dimensions of consumption utility. For any consumption-utility outcome $k^{i}$ and probability distribution over consumption utilities $F^{i}$ in dimension $i$, we define

$$
U\left(k^{i} \mid F^{i}\right)=\int_{r^{i}} u\left(k^{i} \mid r^{i}\right) d F^{i}\left(r^{i}\right)
$$

and define total utility from outcome $\left(k^{v}, k^{p}\right)$ as $U\left(k^{v} \mid F^{v}\right)+U\left(k^{p} \mid F^{p}\right)$. In evaluating $\left(k^{v}, k^{p}\right)$, the consumer compares it to each possibility in the reference lottery. If she had

\footnotetext{
${ }^{4}$ Consistent with most of the evidence and literature on loss aversion, which suggests that individuals are loss-averse even for small stakes, we assume a kink in gain-loss utility at zero. An alternative specification is one in which the marginal gain-loss utility changes quickly around zero, but there is no kink. The mechanism behind our results indicates that in such an alternative specification, charging random sale prices and separate regular prices would still be optimal. In a setting with cost uncertainty and downward-sloping demand, however, the regular prices would no longer be fully sticky, only compressed relative to what one would expect in a classical model.

${ }^{5}$ Specifically, it is key to explaining the endowment effect - that randomly assigned "owners" of an object value it more highly than "nonowners"-and other observed regularities in trading behavior. The common and intuitive explanation of the endowment effect is that owners construe giving up the object as a painful loss that counts more than money they receive in exchange, so that they demand a lot of money for the object. But if gains and losses were defined over the value of the entire transaction, owners would not be more sensitive to giving up the object than to receiving money in exchange, so no endowment effect would ensue.
} 
been expecting to pay either $\$ 15$ or $\$ 20$ for the product, for example, paying $\$ 17$ for it feels like a loss of $\$ 2$ relative to the possibility of paying $\$ 15$, and feels like a gain of $\$ 3$ relative to the possibility of paying $\$ 20$. In addition, the weight on the loss in the overall experience is equal to the probability with which she had been expecting to pay $\$ 15$.

To complete our theory of consumer behavior with the above belief-dependent preferences, we specify how beliefs are formed. Still applying Kőszegi and Rabin (2006), we assume that beliefs must be consistent with rationality: the consumer correctly anticipates the implications of her period- 0 plans and makes the best plan she knows she will carry through. While the formal definitions below are notationally somewhat cumbersome, the logical consequences of this requirement are intuitively relatively simple. Note that any plan of behavior formulated in period 0 -which in our setting amounts simply to a strategy of which prices to buy the product for-induces some expectations in period 0 . If, given these expectations, the consumer is not willing to follow the plan, then she could not have rationally formulated the plan in the first place. Hence, a credible plan in period 0 must have the property that it is optimal given the expectations generated by the plan. Following original definitions by Kosszegi (2010) and Kőszegi and Rabin (2006), we call such a credible plan a personal equilibrium (PE). Given that she is constrained to choose a PE plan, a rational consumer chooses the one that maximizes her expected utility from the perspective of period 0 . We call such a favorite credible plan a preferred personal equilibrium (PPE).

Formally, notice that whatever the consumer had been expecting, in period 1 she buys at prices up to and including some cutoff (recall that the consumer's indifference is broken in favor of buying). Hence, any credible plan must have such a cutoff structure. Consider, then, when a plan to buy up to the price $p^{*}$ is credible. This plan induces an expectation $F^{v}\left(\Pi, p^{*}\right)$ of getting consumption utility $v$ from the product with probability $\Pi\left(p^{*}\right)$, and an expectation $F^{p}\left(\Pi, p^{*}\right)$ of spending nothing with probability $1-\Pi\left(p^{*}\right)$ and spending each of the prices $p \leq p^{*}$ with probability $\operatorname{Pr}_{\Pi}(p)$. The plan is credible if, with a reference point given by these expectations, $p^{*}$ is indeed a cutoff price in period 1 :

Definition 1. The cutoff price $p^{*}$ is a personal equilibrium (PE) for price distribution $\Pi$ if for the induced expectations $F^{v}\left(\Pi, p^{*}\right)$ and $F^{p}\left(\Pi, p^{*}\right)$, we have

$$
U\left(0 \mid F^{v}\left(\Pi, p^{*}\right)\right)+U\left(0 \mid F^{p}\left(\Pi, p^{*}\right)\right)=U\left(v \mid F^{v}\left(\Pi, p^{*}\right)\right)+U\left(-p^{*} \mid F^{p}\left(\Pi, p^{*}\right)\right)
$$

Now utility maximization in period 0 implies that the consumer chooses the PE plan that maximizes her expected utility:

Definition 2. The cutoff price $p^{*}$ is a preferred personal equilibrium (PPE) for price distribution $\Pi$ if it is a PE, and for any PE cutoff price $p^{* *}$,

$$
\begin{aligned}
E_{F^{v}\left(\Pi, p^{*}\right)}\left[U\left(k^{v} \mid F^{v}\left(\Pi, p^{*}\right)\right)\right]+E_{F^{p}\left(\Pi, p^{*}\right)}\left[U\left(k^{p} \mid F^{v}\left(\Pi, p^{*}\right)\right)\right] \\
\quad \geq E_{F^{v}\left(\Pi, p^{* *}\right)}\left[U\left(k^{v} \mid F^{v}\left(\Pi, p^{* *}\right)\right]+E_{F\left(\Pi, p^{* *}\right)}\left[U\left(k^{p} \mid F^{v}\left(\Pi, p^{* *}\right)\right)\right] .\right.
\end{aligned}
$$


The monopolist is a standard risk-neutral profit-maximizing firm, trying to maximize expected profits given the consumer's behavior. To be able to state the monopolist's problem simply as a maximization problem rather than as part of an equilibrium, we assume that the consumer chooses the highest-purchase-probability PPE. With this assumption, the monopolist solves

$$
\max _{\Pi}\left\{\Pi\left(p^{*}\right) E_{P}\left[p \mid p \leq p^{*}\right]-\Pi\left(p^{*}\right) c \mid p^{*} \text { is the highest PPE for } \Pi(\cdot)\right\} .
$$

To facilitate our statements and proofs, we make one more technical assumption: we suppose that the monopolist must choose a discrete price distribution in which neighboring atoms are at least $\Delta>0$ apart. We think of $\Delta$ as being small. Together with the assumption that indifference by the consumer is broken in favor of buying, this ensures the existence of an optimal price distribution. In the Appendix, we identify properties of the optimal price distribution for $\Delta>0$, but in the text, we state these results in a more transparent form, in the limit as $\Delta$ approaches zero.

Definition 3. The price distribution $\Pi(\cdot)$ is limit-optimal if there exist a sequence $\Delta_{i} \rightarrow 0$ and optimal price distributions $\Pi_{i}(\cdot)$ for each $\Delta_{i}$ such that $\Pi_{i} \rightarrow \Pi$ in distribution.

\section{The OPtimal PRiCE Distribution}

This section presents our main results on pricing with loss-averse consumers. We begin in Section 4.1 by illustrating the main idea behind random sales in a simplified model with no loss aversion in money. In Section 4.2, we identify the limit-optimal price distribution in our main model.

\subsection{An illustration: No loss aversion in money}

We illustrate the logic behind the role of randomization in the monopolist's optimal pricing strategy in a model with no loss aversion in money. This variant of our model simplifies many calculations, and is also relevant because, as argued for instance by Novemsky and Kahneman (2005) and Kőszegi and Rabin (2009), loss aversion may be weaker in the money than in the product dimension. We assume that for riskless reference points $r^{v}$ and $r^{p}$, the consumer's gain-loss utility in the product dimension is $k^{v}+\mu\left(k^{v}-r^{v}\right.$ ) (as above), but in the money dimension it is simply $k^{p}+\eta \cdot\left(k^{p}-r^{p}\right)$. We define gain-loss utility for stochastic reference points analogously to above.

Because in this variant the consumer's disutility of paying a price $p$ is $(1+\eta) p$ independently of $r^{p}$, her willingness to pay for the product depends only on $r^{v}$. To see the effect of this reference point, suppose that the consumer had expected to buy with probability $q$. Then, if she buys, her utility in the product dimension-consisting of consumption utility and a gain of $v$ relative to the possibility of not buying she had expected with probability $1-q$-is $(1+(1-q) \eta) v$, and if she does not buy, her utility in the product dimension-consisting of a loss of $v$ relative to the possibility of 
buying she had expected with probability $q$-is $-q \eta \lambda v$. Hence, the consumer buys if $(1+\eta) p \leq(1+\eta+\eta(\lambda-1) q) v$, or

$$
p \leq \frac{(1+\eta+\eta(\lambda-1) q) v}{1+\eta} .
$$

To see what this endogenous willingness to pay implies for pricing, first consider what the monopolist can do with a deterministic price $p$. In that case, the consumer faces a deterministic environment, so in any PE she gets what she expects. ${ }^{6}$ This implies that her PE total utility is equal to her consumption utility, so that from an ex ante perspective, buying is optimal if and only if $p \leq v$. To conclude that buying is the PPE if and only if $p \leq v$, however, we must check that this constitutes a PE for any $p$. This is easy: for $p>v$, the inequality (2) implies that the consumer is willing to follow a plan to buy with probability $0(q=0)$, and for $p \leq v$, the same inequality implies that the consumer is willing to follow a plan to buy with probability $1(q=1)$. Hence, the highest revenue the monopolist can earn with a deterministic price is $v$.

But the monopolist can do better with a stochastic price. Suppose that the monopolist charges $p=v$ with probability $s_{1}$, and higher prices (whose distribution we determine momentarily) starting at $v+\Delta$ with probability $1-s_{1}$. Then, in any PE, the consumer buys at price $p=v$ : by inequality (2), even if she had expected to buy with probability 0 , she would buy at price $v$. Given that the consumer therefore buys with probability of at least $s_{1}$ in any PE, inequality (2) implies that it is not credible for her not to buy at price $v+\Delta$ if

$$
v+\Delta \leq \frac{\left(1+\eta+\eta(\lambda-1) s_{1}\right) v}{1+\eta} \Leftrightarrow s_{1} \geq \frac{1+\eta}{\eta(\lambda-1) v} \Delta .
$$

Intuitively, the consumer's realization that she will buy at price $v$ raises her reference point in the product dimension and thereby creates a sense of loss if she does not buy. The motive to avoid this loss induces an "attachment effect" that raises her willingness to pay for the product.

Extending the above logic to any price distribution is straightforward. Suppose that the consumer faces the distribution $F(\cdot)$ and define $F_{-}(p)=\lim _{p^{\prime} \nearrow p} F\left(p^{\prime}\right)$. Then there is a unique PE in which the consumer buys with probability 1 if and only if

$$
p \leq \frac{\left(1+\eta+\eta(\lambda-1) F_{-}(p)\right) v}{1+\eta} \Leftrightarrow F_{-}(p) \geq \frac{1+\eta}{\eta(\lambda-1)} \cdot \frac{p-v}{v}
$$

holds for all $p$ on the support of $F(\cdot)$. A "near-uniform" distribution that puts weights of $(1+\eta) \Delta /(\eta(\lambda-1) v)$ on each of the prices $v, v+\Delta, v+2 \Delta, \ldots$ and puts the remaining weight on the highest price, satisfies this condition with equality at each of the atoms.

Notice that when facing the above price distribution, the consumer buys the product at an average price that exceeds $v$, so that she receives negative expected utility. In fact, for small $\Delta$ the consumer pays a price strictly above $v$ with probability close to 1 ! Because the consumer has the option of making and following through on a strategy of

\footnotetext{
${ }^{6}$ This is true because-due to our assumption that indifference by the consumer in period 1 is broken in favor of buying-there are only pure-strategy PE.
} 
never buying — which would yield an expected utility of 0 - this means that she behaves suboptimally among the strategies available to her. Intuitively, the monopolist exploits a novel type of time inconsistency that arises in our model despite a rational consumer's attempt to maximize a single well defined utility function. ${ }^{7}$ While the increase in the consumer's reference point due to the expectation to buy at low prices increases her willingness to pay, it also lowers her utility. When she makes her purchase decision in period 1 , she takes the reference point (formed in period 0 ) as given and therefore ignores this negative effect.

Adding loss aversion in money complicates the above logic that underlies randomization for two reasons. First, because a consumer who did not expect to buy experiences a loss in money if she does buy, loss aversion in money reduces the highest price at which it is not credible not to buy. Second, once the consumer expects to buy at such a low price, she experiences paying higher prices as a loss, reducing the monopolist's ability to cash in on the attachment effect. Nevertheless, our main result below shows that for any loss-averse preferences by the consumer, a stochastic price remains optimal. Furthermore, our main result shows that the optimal price distribution features not only a densely packed region of sale prices similar to the uniform distribution above, but also a regular-price atom separated from the sale prices.

\subsection{Main result}

Our main proposition identifies the features of the monopolist's limit-optimal pricing strategy when the consumer is loss-averse in the money as well as the product dimension.

Proposition 1. Fix any $\eta>0$ and $\lambda>1$. The profit-maximizing price distribution induces purchase with probability 1. Furthermore, in that case, any limit-optimal price distribution $\Pi(\cdot)$ has support $\left[p_{\text {sale }}^{l}, p_{\text {sale }}^{h}\right] \cup\left\{p_{\text {reg }}\right\}$, where $p_{\text {sale }}^{l}=\underline{p}=(1+\eta) v /(1+\eta \lambda)<$ $p_{\text {sale }}^{h}<p_{\text {reg }}$ and $\Pi(\cdot)$ is continuously distributed on the interval $\left[\bar{p}_{\text {sale }}^{l}, p_{\text {sale }}^{h}\right]$ with density $\pi(p)=(1+\eta \lambda) /[\eta(\lambda-1)(v+p)]$. The monopolist's expected revenue is strictly greater than $v$.

Proposition 1 says that the limit-optimal price distribution has two parts (as illustrated in Figure 1): an interval of continuously distributed low prices and a single atomic high price. Furthermore, there is a gap between the low price interval and the price atom. Thinking of the low prices as the nonsticky sale prices and of the high isolated pricing atom as the sticky regular price, this price distribution is broadly consistent with the evidence on supermarket pricing summarized in Section 2.

The proof of Proposition 1 has five main steps: (i) with a deterministic price, the monopolist cannot earn more than $v$; (ii) the firm can earn more than $v$ with a stochastic price distribution for which it is not credible for the consumer not to buy at low (sale)

\footnotetext{
${ }^{7}$ That beliefs-based preferences can generate time-inconsistent behavior is pointed out by Caplin and Leahy (2001) and Kőszegi (2010), and explored in more detail by Kőszegi (2010) and Kőszegi and Rabin (2009).
} 
prices; (iii) it is optimal to make these "forcing" sale prices-i.e., the prices at which the consumer buys in any PE-stochastic; (iv) it is suboptimal to rely solely on forcing sale prices, so that there is also a region of high regular prices separated from the sale prices; and (v) the high regular price is sticky. We discussed the intuition for steps (i), (ii), (iii), and (v) in the Introduction, so here we discuss only step (iv).

To understand step (iv), suppose, to the contrary, that a forcing distribution-i.e., a price distribution that consists entirely of forcing prices and hence induces a unique PE in which the consumer buys at all prices-is optimal. By steps (i) and (ii), its average price must then be greater than $v$. To get a contradiction, we argue that the consumer will still buy at all prices if the monopolist raises the highest price $p$ in the distribution to some $p^{\prime}>p$ while leaving the rest of the distribution unchanged. By the definition of forcing, $p$ is such that the consumer buys at $p$ if she had been expecting to buy at prices less than $p$. Then, because the attachment effect implies that expecting to buy at $p^{\prime}$ raises the consumer's willingness to pay for the product, there is a range of $p^{\prime}>p$ such that buying at all prices remains a PE (albeit not the only one). Now notice that expecting to buy at $p^{\prime}$ has a positive effect on utility when buying: besides generating gains in money, it eliminates losses in money and gains in the good, and since the average price is greater than $v$, the elimination of losses dominates. This means that for $p^{\prime}$ sufficiently close to $p$, the consumer prefers a plan to buy at all prices rather than only at prices below $p$, so that buying at all prices is the PPE.

As the above intuition indicates, the prediction of our model that there is an atomic regular price separated from the sale prices does not rely on loss aversion in money: even if the consumer's disutility from monetary losses was equal to her utility from gains, the motive to eliminate these losses would lead her to buy at the higher price $p^{\prime}$. This is straightforward to check in the version of our model in Section 4.1 with no loss aversion in money. But as the same intuition indicates, the regular price does rely on gain-loss utility in money: if the consumer did not derive disutility from paying a higher price than her reference point, she would not care about the above losses and hence she would prefer not to buy at $p^{\prime}$. To see this formally, we return to a subtle modification of our model in Section 4.1: we assume that the consumer's utility in money is not referencedependent, but simply equal to $(1+\eta) k_{p}$. This implies that for any price distribution, the consumer's set of PE is the same as in Section 4.1 and the optimal deterministic price remains $v$. Nevertheless, absent reference-dependence in money, we now show that the monopolist does not want to charge a regular price. Suppose that for some $p^{*}>v$ with $F\left(p^{*}\right)<1$, there is a PE such that the consumer buys only for prices $p \leq p^{*}$. We argue that for any $p^{\prime}>p^{*}$ with $F\left(p^{\prime}\right)>F\left(p^{*}\right)$, buying up to prices $p^{\prime}$ cannot be a PPE. For notational simplicity, we denote by $V\left(p^{\prime} \mid p\right)$ the consumer's expected utility if she had formed expectations based on the plan to buy up to price $p$ and then follows a plan to buy up to price $p^{\prime}$. In this notation, we have $V\left(p^{*} \mid p^{*}\right) \geq V\left(p^{\prime} \mid p^{*}\right)>V\left(p^{\prime} \mid p^{\prime}\right)$, where the first inequality follows from the definition of $\mathrm{PE}$ and the second inequality follows from the fact that planning to buy for prices up to $p^{\prime}$ rather than $p^{*}$ raises the consumer's reference point in the product dimension and hence lowers her utility. This means that with no gain-loss utility in money, the optimal price distribution induces a unique PE 
with purchase with probability 1 (much like the price distribution we identified in Section 4.1), and the firm's limit-optimal price distribution is the uniform distribution with support $[v,(1+\eta \lambda) v /(1+\eta)]$.

The qualitatively different nature of the optimal price distribution with and without gain-loss utility in money also reflects a subtle difference in how the monopolist exploits the consumer's attachment to the product to charge an expected price above $v$. In each case, the possibility of buying the product at a low price means that the consumer must expect to get the product with some probability. Without gain-loss utility in money, the monopolist exploits the consumer's ex post (period-1) aversion to facing a sense of loss in the product dimension to charge higher prices. With gain-loss utility in money, the monopolist relies on this ex post aversion to losses in the sales region, but the same aversion is insufficient to induce the consumer to buy at the regular price: if she expected not to buy at the regular price, she would strictly prefer not to do so ex post. Instead, the monopolist relies on the consumer's ex ante (period-0) aversion to risk in whether she will get the product to induce her to plan on buying at the regular price.

An interesting possibility arises in our model if $c>p$, yet the monopolist can profitably sell to the consumer. In this case, the monopolist's cost is higher than some of the prices it charges, providing a nonpredatory rationale for potential below-marginal-cost pricing of a single-product firm. Going further, since the monopolist induces the consumer to buy at an average price that exceeds $v$, it may sell the product even if $v<c$. In this case, loss aversion affects not only the monopolist's pricing strategy, but also its production decision, leading it to produce a socially wasteful product. Finally, note that if below-marginal-cost pricing is prohibited-as is the case in some countries-sales disappear altogether: since the firm cannot manipulate the consumer into buying against her will, it chooses a sticky price if $v>c$ and chooses not to sell if $v<c .^{8}$

Beyond the shape of the optimal price distribution, the observation that the consumer buys at an expected price that exceeds $v$ has an immediate welfare implication:

Proposition 2. For any $\eta>0, \lambda>1$, and $\Delta<v-p$, the consumer would be better of expecting and following through on a strategy of never buying than expecting and following through on her actual strategy of buying at all prices.

Proposition 2 identifies a sense in which the firm's sales are manipulative: they lead the consumer to buy the product even though she would prefer not to. ${ }^{9}$ Two caveats

\footnotetext{
${ }^{8} \mathrm{~A}$ related point is that with cost uncertainty, the firm's opportunity cost of delivering the product could sometimes be greater than the highest possible price. This could occur either because the firm itself faces high costs or because it has another consumer with high valuation. In a classical setting, the firm would not sell to the consumer in these contingencies. But in our theory, not getting the product in some states reduces the consumer's willingness to pay in other states, so the monopolist may commit to selling even in situations in which it makes losses from doing so.

${ }^{9}$ Although we model neither multiproduct retailers nor the wholesaler-retailer relationship, Proposition 2 suggests that retailers may benefit less from sales than wholesalers: if welfare-reducing manipulative sales induce some consumers to avoid visiting the retailer, they lower profits from other wholesalers' products. One would then expect wholesalers to encourage the use of sales in their contracts with downstream retailers.
} 
regarding this result are in order. First, the extreme version of the result-that the firm does only harm to the consumer by selling to her-clearly relies on our assumption that the firm knows the consumer's preferences perfectly. Consumers with much higher valuation than the range of possible prices would clearly be better off buying than not buying. ${ }^{10}$ Second, it matters what the consumer would do with the money if she did not buy from this firm. Given that we assume linear consumption utility in money, the implicit assumption in our model is that the consumer would spend her money on an alternative divisible product that is available on the market at a deterministic price. But if she would be manipulated into buying something else from another firm, she might be better off buying from this firm.

\section{EXTENSIONS AND MODIFICATIONS}

In this section, we discuss a number of further predictions of our framework.

\subsection{Competition}

Our main analysis focuses on the case of a monopolistic retailer. While the general question of how competition affects pricing is beyond the scope of the current paper, we discuss two simple forms of competition, showing that our results on random sales rely on some amount of market power. First, we consider perfect ex ante competition for consumers, as, for example, when consumers decide which supermarket or restaurant to frequent. Two retailers simultaneously commit to their price distributions, and after observing the distributions, the consumer decides which retailer to visit and forms expectations about her consumption outcomes. We assume that if indifferent, the consumer visits each firm with positive probability. Finally, a price is drawn from each retailer's price distribution, and the consumer decides whether to buy at her previously chosen retailer's price. We assume that the two retailers have identical costs $c<v$ and that they use pure strategies (i.e., they do not mix between distributions). Then:

Proposition 3. For any $\eta>0$ and $\lambda>1$, the unique equilibrium with ex ante competition is for each firm to choose the deterministic price $c$.

Proposition 3 says that if there is perfect competition, firms do not use a manipulative price distribution, but instead choose the deterministic price equal to cost. The reason is simple: a manipulative price distribution would lead the consumer to visit the other retailer.

Second, we discuss a form of imperfect competition. Suppose the monopolist faces a competitive fringe: there is a competitive industry that produces a substitute product that has a lower consumption value $v_{f}<v$ on the same dimension as the monopolist's product, the consumer is interested in buying at most one of the products, and she decides which one to buy after seeing both prices. The competitive fringe charges a low

\footnotetext{
${ }^{10}$ Nevertheless, even with consumer heterogeneity, some (marginal) consumers who buy with positive probability would be better off making and following through on a plan of never buying. See our working paper (Heidhues and Kőszegi 2011) for details.
} 
price $p_{f} \leq(1+\eta) v_{f} /(1+\eta \lambda)$. In this case, whatever the consumer had expected, she prefers to buy the fringe's good to not consuming. Hence, in any PE, she buys one of the products, getting intrinsic utility of at least $v_{f}$. As a result, the firm's problem can be thought of as choosing the distribution of the price premium $p-p_{f}$ it charges for the incremental consumption value $v-v_{f}$. Therefore, the optimal price distribution is the same as that of a monopolist who sells a product of value $v-v_{f}$, shifted to the right by $p_{f}$ : it has the same shape and probability of sales as the optimal price distribution in our basic model, but it is more compressed.

\subsection{Price stickiness}

As intuited by researchers for a long time and shown, for instance, by Sibly (2002) and Heidhues and Kőszegi (2008), consumer loss aversion often creates "price stickiness"an unresponsiveness of prices to changes in cost or demand circumstances. While the main point of this paper is that loss aversion can create the opposite incentive-to introduce uncertainty into a deterministic environment despite facing a consumer who dislikes this uncertainty - we conjecture that the price variation we identify in this paper is consistent with stickiness in the regular price and in price stickiness in a competitive environment. Intuitively, not only does a monopolist not need variation in the regular price (as we explained above), it has an incentive to keep the regular price sticky to induce the consumer to buy at the regular price in addition to the sale prices. If the regular price was uncertain, the consumer would experience a gain if it turned out to be relatively low and experience a loss if it turned out to be relatively high. Due to loss aversion, she would feel the loss more heavily, making her less willing to buy at an uncertain regular price. Similarly, because a consumer dislikes uncertainty in the price, to attract her from a competitor a firm has an incentive to eliminate variation in the price, leading to sticky prices under ex ante competition. These intuitions suggest that our model is consistent with the puzzling combination of stickiness and flexibility in prices.

To demonstrate these forces toward price stickiness formally in our model, it is necessary to introduce features that in a classical setting would lead to price variation. A natural way to do so is to assume that demand is downward sloping and the firm's cost is uncertain. We have, however, been unable to analyze models with these features, in general, and even special cases raise considerable technical issues. We describe here two restrictive cases we have analyzed in detail in our working paper (Heidhues and Kőszegi 2011). In the monopoly case, we restrict attention to price distributions in which the prices $p_{L}-\alpha_{L}, p_{L}+\alpha_{L}, p_{H}-\alpha_{H}$, and $p_{H}+\alpha_{H}$ are charged with probabilities $s / 2, s / 2$, $(1-s) / 2$, and $(1-s) / 2$, respectively. Constrained by the exogenous bound $\bar{\alpha}>0$, the firm chooses $s \in[0,1), p_{L}, p_{H}, \alpha_{L}$, and $\alpha_{H}$ that satisfy $p_{H}>p_{L}+2 \bar{\alpha}$ and $0 \leq \alpha_{L}, \alpha_{H} \leq \bar{\alpha}$. In this setting, we show that if $\bar{\alpha}$ is sufficiently small, the optimal price distribution has a sales-and-regular-prices structure $(s>0)$ and a single regular price $\left(\alpha_{H}=0\right)$, and if in addition the firm's marginal cost is sufficiently narrowly distributed, sales prices are flexible $\left(\alpha_{L}=\bar{\alpha}\right)$. These findings contrast with those in the corresponding classical model, where for sufficiently narrowly distributed costs, sale prices would not be used $(s=0)$, but the regular price would adjust to cost shocks $\left(\alpha_{H}>0\right)$. 
In the competition case, we consider a variant of our model in Section 5.1 in which there is a mass of consumers whose consumption value is distributed continuously on the interval $[0, \bar{v}]$, with positive density everywhere, and the firms have identical cost distributions uniformly distributed on the interval $\left[c_{L}, c_{H}\right]$ with density $d$. We show that if $d$ is sufficiently large, then for any $\Delta>0$, the unique symmetric equilibrium is for each firm to choose the deterministic price $\left(c_{L}+c_{H}\right) / 2 .{ }^{11}$

\subsection{Further extensions and modifications}

An implicit assumption of our model above is that it is costless for the consumer to observe the price in period 1. In contrast, consumers often have to go out of their way to learn a particular product's price. We formally analyze a variant of our model with such price-discovery costs in our working paper (Heidhues and Köszegi 2011) and demonstrate that for low price-discovery costs, the limit-optimal price distribution is very similar to the one we find in Proposition 1, with one important difference: the monopolist charges a price of zero with small probability. Intuitively, the possibility of a "free sample" makes nonbuying noncredible despite price-discovery costs because the consumer-even if she had been expecting not to do so-would want to pay the small price-discovery cost in period 1 to see whether she can get the free sample. ${ }^{12}$ In contrast, when price-discovery costs are high, it becomes too costly or impossible to manipulate the consumer into buying against her will through a sales-and-regular-price strategy, so that the firm switches to deterministic pricing. This is easiest to see when price-discovery costs are greater than $p$ : in this case, a strategy of never buying is always credible, so that it is impossible to manipulate a consumer into buying against her will. Our framework, therefore, has the novel prediction that sales are more likely when price discovery costs are low. This is arguably the case in supermarkets for the marginal consumer of any given product-as long as these consumers are visiting the supermarket to buy other products anyhow-but is arguably not the case for many other retailers.

In our basic model, we have taken the representative consumer's consumption value $v$ to be deterministic. Suppose instead that $v$ is uncertain. We can distinguish two cases, depending on whether the consumer knows $v$ in advance (in period 0 ). If she does not, then (although we have not analyzed such a model in detail) the same forces as with cost uncertainty are likely to operate, so that a qualitatively similar price distribution likely results. If the consumer does know $v$ in advance, then from the perspective of our model, each $v$ can be thought of as a different pricing situation, in each of which the

\footnotetext{
${ }^{11}$ Note that sticky pricing is not an equilibrium in this model when consumers have classical referenceindependent preferences, even if these consumers are risk-averse with respect to the surplus from the transaction or the price to be paid for the product. If a firm charges the deterministic price equal to average cost, its competitor can profitably deviate by offering lower prices when its costs are lower, attracting some consumers whose value is below the average cost.

${ }^{12}$ While we provide an explanation for free samples, this prediction is not robust to realistic variations of our model in which a free sample would generate extra money-losing demand, for instance, by attracting low-valuation consumers or by inducing consumers to store. When these considerations are important, the firm will use a positive (but low) price atom instead or switch to deterministic pricing.
} 
monopolist chooses the optimal price distribution we derived for that $v$. For example, as we discussed, if price-discovery costs are high our theory predicts a (different) sticky price for each $v$. This prediction is consistent with matinees in movie theaters and cyclical sales of many products for which the sale price is also sticky. At the same time, our model does not explain why prices do not seem to change in response to some other predictable changes in demand.

\section{Related literature}

In this section, we discuss the literatures most closely related to our paper.

\subsection{Loss aversion}

Loss aversion is a natural explanation for the endowment effect, small-scale risk aversion, and other widely observed patterns in individual behavior, and seems to contribute to consumer behavior in the marketplace. ${ }^{13}$ Beyond this extensive evidence on the phenomenon of loss aversion in general, more recent evidence lends support to Köszegi and Rabin's (2006) particular, expectations-based model of referencedependent preferences and loss aversion. In Abeler et al.'s (2011) experiment, subjects work on a boring task for a piece rate and can choose when to stop. When they are done, a coin flip determines whether they receive what they earned or a predetermined amount, where the predetermined amount is set to be $€ 3.50$ for one group and $€ 7.00$ for another group. A significant number of subjects stop working when they have earned exactly the predetermined amount, suggesting that this expected amount became (part of) their reference point for earnings. In a simple exchange experiment, Ericson and Fuster (2011) find that subjects are more likely to keep an item they had received if they had been expecting a lower probability of being able to exchange it, consistent with the idea that their expectations affected their reference point. ${ }^{14}$ Crawford and Meng (2011) propose a model of cab drivers' daily labor-supply decisions in which cab drivers have rational-expectations-based reference points ("targets") in both hours and income. Crawford and Meng show that by making predictions about which target is reached first given the prevailing wage each day, their model can reconcile the controversy between Camerer et al. (1997) and Farber $(2005,2008)$ in whether cab drivers have referencedependent preferences.

\footnotetext{
${ }^{13}$ Kahneman et al. $(1990,1991)$, for instance, find in a series of experiments that randomly assigned owners of an object value it more highly than nonowners, presumably because owners construe giving up the object as a loss. In addition, as argued by Rabin (2000a), Rabin and Thaler (2001), Barberis et al. (2006), and other researchers, the most significant source of aversion to risk over modest stakes is loss aversion. Additionally, research in marketing suggests that consumers are loss-averse in their evaluation of market prices (Erickson and Johansson 1985, Winer 1986, Kalwani and Yim 1992, Hardie et al. 1993), with their "reference price" determined at least partly by expectations (Jacobson and Obermiller 1990).

${ }^{14}$ In an alternative experiment, Ericson and Fuster (2011) find that-consistent with the attachment effect-subjects are willing to pay 20-30\% more for an object if they had expected to be able to get it with 80-90\% rather than 10-20\% probability. In a similar experiment, however, Smith (2008) does not find the same effect.
} 
Several papers investigate firm pricing behavior when consumers are loss-averse, typically concluding that firms have an incentive to "insure" consumers against exogenous uncertainty. Sibly (2002), Heidhues and Kőszegi (2005), and Spiegler (2012b) show that loss aversion can generate price stickiness. In Heidhues and Kőszegi (2008), we consider a model of oligopolistic competition with differentiated products and show that due to consumer loss aversion, demand is more elastic at higher than at lower market prices, leading firms to reduce or eliminate price variation across products. This can explain why competitors often sell differentiated goods at identical prices-even in environments that are not perfectly symmetric. ${ }^{15}$ Herweg and Mierendorff (2013) argues that the prevalence of flat-rate contracts can be due to consumer loss aversion, and Herweg et al. (2010) and Macera (2012) demonstrate that with employee loss aversion, optimal incentive contracts feature less variation in the wage than would be expected based on classical models. In contrast to the above literature-much of which employs an expectations-based model of loss aversion-this paper highlights that expectationsbased loss aversion can induce a firm to optimally introduce risk into an otherwise deterministic environment.

\subsection{Theories of pricing}

There is a considerable industrial-organization literature that investigates why firms engage in sales. The most important and most common explanation is based on firms' incentive to price discriminate between groups of consumers. In Conlisk et al.'s (1984) model of a durable-goods monopolist, for example, a new cohort of heterogeneous consumers enters the market in each period and each consumer decides whether to buy the good immediately or after some delay. In most periods the monopolist sells to highvaluation buyers only, but in some periods it lowers its price to sell to the accumulated low-valuation consumers. ${ }^{16}$ Intertemporal-price-discrimination models clearly capture a realistic and important feature that is missing from our model, and in this sense we view them as complementary to our theory.

There is also a set of models in industrial organization in which the oligopolistic environment leads firms to play mixed strategies. ${ }^{17}$ In all of these papers, each firm is left

\footnotetext{
${ }^{15}$ Karle and Peitz (2010) qualify Heidhues and Kőszegi's (2008) prediction of reduced price variability by showing that in some asymmetric duopolistic environments-specifically, when consumers observe prices but not how much they will like each product before their expectations-based reference point is set-consumer loss aversion can actually increase price differences. Deviating from the expectations-based model, Zhou (2011) assumes that consumers take the first or most prominent price they see as the reference point for money outlays. Because the leading firm benefits a lot from having a lower price than its competitor and is hurt less by having a higher price, it has an incentive to avoid charging the same price, so that in a simultaneous-move game, it sets a random price.

${ }^{16}$ Conlisk et al. (1984) assume that high-valuation consumers purchase immediately unless the price exceeds their value. Sobel $(1984,1991)$ relaxes this assumption and shows that stationary equilibria still involve price cycles, while a folk-theorem result obtains for nonstationary equilibria. Pesendorfer (2002) shows that an intertemporal-price-discrimination model with storage by consumers matches pricing and consumer behavior in the market for ketchup quite well.

${ }^{17}$ See, for example, Shilony (1977), Varian (1980), Gal-Or (1982), Davidson and Deneckere (1986), and Baye et al. (1992).
} 
with a "captive" group of consumers who will not buy from a cheaper rival and a "noncaptive" group for which firms engage in price competition. In equilibrium, firms randomize between charging the monopoly price for the captive consumers and competing for the noncaptive consumers. ${ }^{18}$

A distinct testable implication of our model relative to most models of sales above is that the monopolist makes higher profits at high prices than at low prices. Intertemporal-price-discrimination models predict the opposite: in those models, a low price today decreases future profits by inducing some consumers to buy now rather than later, so that a firm is willing to set a low price only if compensated by higher current profits. In addition, by the nature of a mixed-strategy equilibrium, mixed-strategy models predict equal profits for low and high prices. While we are unaware of systematic empirical evidence on profits in sale periods relative to regular-price periods, it seems plausible that for at least some types of sales, profits are higher at regular prices. For instance, sales that are subject to strict "limited availability" presumably generate the most profits once the item on sale runs out. ${ }^{19}$ Furthermore, unlike our theory the above models of sales do not seem to predict stickiness in the regular price when demand is downward sloping and there are cost shocks.

Although in its current form our model is not intended as a basis for a macroeconomic model to study monetary policy, in proposing a possible mechanism for sales and price stickiness it is related to such models. Kehoe and Midrigan (2008) assume that there are two distinct kinds of prices-regular prices and sale prices-and that there are both a menu cost associated with changing the regular price, and a different and lower menu cost associated with having an item on sale. Then the regular price is sticky because it is costly to change, but sale prices are not sticky because (conditional on having a sale) they are costless to change. While Kehoe and Midrigan's theory implies a price distribution similar to ours, it leaves unanswered why there would be two different kinds of prices with different menu costs. Our theory provides a kind of microfoundation for these reduced-form assumptions, and makes a variety of additional predictions on the effects of competition, price-discovery costs, and other forces. ${ }^{20}$

\footnotetext{
${ }^{18}$ In a model that is similar to the mixed-strategy oligopoly pricing models but in which consumers' purchase decisions are based on a naive sampling procedure, Spiegler (2012a) predicts a price pattern similar to ours.

${ }^{19}$ One paper that suggests that sales can increase profits at higher prices is Slade (1999). Slade investigates the prices set for saltine crackers by grocery stores in a small U.S. town. She allows own past prices to have either a negative or a positive effect on current demand. The negative effect allows for the pricediscrimination effects. The positive effect is meant to capture a stock of goodwill, which she argues could arise through "consumer habit formation, product awareness, or brand loyalty," but might also be due to loss aversion as in this paper. In her empirical implementation, she finds evidence that low past prices increase current sales. At the same time, Anderson and Simester (2010) find that mail-order customers who recently bought an item at a high price and later see the item with its price deeply reduced are less likely to order in the future, making sales with deep discounts unprofitable in this industry.

${ }^{20}$ It is important to note, however, that-because gain-loss utility is based on consumption utility and, hence, is defined over real variables-in our model, the price would scale with nominal variables and our result on the stickiness of the regular price is stickiness in the real rather than nominal regular price. This implies that in contrast to the above and many other macroeconomic models, our model does not generate a force that in itself leads to monetary nonneutrality. Whether and how variants of our model—e.g., one in
} 
Nakamura and Steinsson (2011) analyze a repeated price-setting game between a monopolist with privately known cost and a consumer with habit formation. Because the consumer is more willing to consume the firm's product and develop a habit if she believes future prices will be low, the monopolist would like to commit to relatively low future prices. As a result, the monopolist's favorite Markov-perfect equilibrium is one in which it never selects prices above a price cap. At the cap, the price is unresponsive to cost, but below the cap, the price is fully responsive to cost. While Nakamura and Steinsson (2011) do not analyze this possibility, it seems that there could well be higher-profits non-Markov equilibria in which the firm compensates consumers for high current prices by charging lower prices in the future. Furthermore, unless passthrough is very high, their model (unlike ours) predicts frequent sales of considerable magnitude only when there are frequent and considerable changes in marginal costs. And because the price distribution is essentially the distribution of short-run profitmaximizing prices censored at the price cap, their model does not naturally predict a gap between the regular price and the sale prices, as our model does.

Rotemberg (2011) develops a framework in which consumers feel regret when they face an increased price, expect firms to altruistically take these feelings into account, and are willing to punish a non-altruistic firm by not buying. ${ }^{21}$ While Rotemberg does not investigate sales when demand and cost conditions remain unchanged-which is the focus of the current paper-his model can generate price stickiness, explains why prices seem to be more responsive to cost than to demand changes, and yields predictions on circumstances under which firms engage in third-degree price discrimination.

\section{Conclusion}

While our model provides a potential explanation for a number of pricing patterns, there are some patterns it cannot explain. For instance, at many establishments, Persian rugs and furniture seem to be perpetually "on sale" from an essentially fictitious "regular price" that is almost never charged. For these products, consumers are unlikely to know the price distribution, and the perpetual-sale strategy probably aims to manipulate consumers' perceptions about typical prices and quality. In addition, given that volume is, for some items, much higher during sales than when the regular price is charged, it is likely that storage on the part of consumers and intertemporal price discrimination on the part of firms play an important role in sales. An important agenda for future research is to investigate how loss aversion interacts with these other forces. For instance, it seems that loss-averse consumers' dislike of running out of the product or paying a lot for it could strengthen the storage motive.

which consumers are loss-averse over nominal prices and, hence, the nominal regular price is sticky—lead to monetary nonneutrality, and whether and how loss aversion interacts with other forces that can generate monetary nonneutrality, is beyond the scope of this paper.

${ }^{21}$ Rotemberg $(2002,2011)$ investigates the implications of such a fair-pricing model for monetary policy and the frequency and size of price changes. 


\section{Appendix A: Some Preliminaries}

First, we introduce some notation we will use throughout our proofs. For any market price distribution $\Pi$, let $p_{1}$ be the lowest price, $p_{2}$ the second lowest, etc. Let $q_{l}$ be the probability that $p_{l}$ is charged. For notational convenience, let $Q_{l}=\sum_{l^{\prime}=1}^{l} q_{l^{\prime}}$ and $P_{l}=$ $E\left[p_{l^{\prime}} l^{\prime} \leq l\right]$.

For future reference, observe that the ex ante expected utility when facing a market price distribution $\Pi$ and buying at all prices less than or equal to $p_{l}$ is

$$
\begin{aligned}
& E U\left(p_{l} ; \Pi\right)=Q_{l} v-Q_{l} P_{l}-\eta(\lambda-1) Q_{l}\left(1-Q_{l}\right) v \\
& \quad-\eta(\lambda-1) Q_{l}\left(1-Q_{l}\right) P_{l}-\eta(\lambda-1) \sum_{l^{\prime}=1}^{l} \sum_{l^{\prime \prime}=1}^{l^{\prime}} q_{l^{\prime \prime}} q_{l^{\prime}}\left(p_{l^{\prime}}-p_{l^{\prime \prime}}\right) .
\end{aligned}
$$

Finally, buying for all prices less than or equal to $p_{l}$ is a personal equilibrium if, given that the consumer expects to buy for all prices less than or equal to $p_{l}$, she prefers to buy at price $p_{l}$ and prefers not to buy at $p_{l+1}$, where we set $p_{l+1}=\infty$ if $p_{l}$ is the highest price in the market price distribution. Hence, $p_{l}$ is a personal equilibrium cutoff if and only if

$$
p_{l} \leq \frac{1+\eta\left(1-Q_{l}\right)+\eta \lambda Q_{l}}{1+\eta \lambda} v+\frac{\eta(\lambda-1)}{1+\eta \lambda} Q_{l} P_{l}<p_{l+1}
$$

\section{Appendix B: Discrete version of Proposition 1}

To establish Proposition 1, which is stated for the limit-optimal distribution, we begin by stating and proving a version of the proposition for $\Delta>0$ (that is, not in the limit). To state the proposition as well as later results, we define

$$
q^{*}(p)=\frac{A \Delta}{(v+p)},
$$

where $A \equiv(1+\eta \lambda) /(\eta(\lambda-1))$.

We first prove the following proposition. ${ }^{22}$

Proposition 4. For any $\eta>0, \lambda>1$, and $\Delta$ satisfying $0<\Delta<v-p$, if the firm can profitably sell to the consumer, then a profit-maximizing price distribution exists, and induces purchase with probability 1 . In addition, for any profit-maximizing price distribution, there exists a $z>0$ such that the distribution has atoms at $p_{1}, p_{2}, p_{3}, \ldots, p_{z}$ and $p_{z^{*}}>p_{z}$, where $p-2 \Delta<p_{1} \leq p$ and for $2 \leq l \leq z, p_{l}-p_{l-1}<2 \Delta$. For $l<z$, the weight on atom $p_{l}$ is $q_{l}=\bar{A}\left(p_{l+1}-p_{l}\right) /\left(\bar{v}+p_{l}\right)$, the weight on atom $p_{z}$ is $q_{z}<2 A \Delta /\left(v+p_{z}\right)$, and the weight on atom $p_{z^{*}}$ is the complementary probability $1-\sum_{l=1}^{z} q_{l}$.

\footnotetext{
${ }^{22}$ Proposition 4 is stated for any $\Delta>0$. For sufficiently small $\Delta>0$, we know somewhat more about the structure of the optimal price distribution. In particular, using the notation of the proposition, in that case $p_{1}=\underline{p}, p_{l+1}-p_{l}=\Delta$ for any $l<z$, and $q_{z} \leq A \Delta /\left(v+p_{z}\right)$.
} 
Proof. We begin by introducing the formal versions of what in the text we call sale prices and regular prices. Let $Q_{z} \geq 0$ be the highest probability such that in any PE, the consumer buys the product with probability of at least $Q_{z}$. Furthermore, let $Q_{z^{*}} \geq Q_{z}$ be the probability with which she buys the product. Let the corresponding cutoff prices (defined as the highest atoms on the price distribution at which the consumer buys) be $p_{z}$ and $p_{z^{*}}$, respectively, and let $F$ be the optimal price distribution. We think of the prices up to and including $p_{z}$ as the sale prices and of the higher prices as the regular prices. Hence, $Q_{z}$ is the probability of buying on sale, and $Q_{z^{*}}-Q_{z}$ is the probability of buying at the regular prices.

It is useful to first outline the broad steps in our proof. There are two major steps, and several substeps. The main parts of the proof correspond to steps (i)-(v) that provide the intuition for Proposition 1. For technical reasons, however, the order of the steps is not exactly the same and there are also other steps.

Part A. We show that any profit-maximizing price distribution has the properties identified in the proposition. We do so by showing that for any other distribution, there is a distribution satisfying these properties that yields higher profits. This is the key part of the proof. We use the following substeps:

A(i). We show that there must be a single atom on the interval $\left(p_{z}, p_{z^{*}}\right]$, that is, there must be a single regular price. This corresponds to step (v) in the main text.

A(ii). We establish the (intuitively obvious) result that the consumer buys with probability $1\left(Q_{z^{*}}=1\right)$.

From here, the proof corresponds to steps (i)-(iv) of the intuition in the text.

A(iii). We show that with a deterministic price, the firm cannot earn revenue greater than $v$ (step (i)).

A(iv). We show that if $\Delta$ is sufficiently small, the firm charges at least two prices with positive probability, establishing that $Q_{z}>0$ (step (ii)).

$A(v)$. We show that the sale prices are at most $2 \Delta$ apart and have the property that if the consumer expected to buy up to some sale price, she would just be willing to buy at the next sale price (step (iii)).

A(vi). We establish that it is not optimal to set $Q_{z}=1$ (step (iv)).

Part B. We show that among price distributions that satisfy the properties of the proposition, a profit-maximizing price distribution exists.

Part A. A(i). First, we show that there must be a single atom on the interval ( $\left.p_{z}, p_{z^{*}}\right]$ because otherwise the monopolist could replace the stochastic prices with a single higher average price without eliminating the PPE, increasing revenues. To see this formally, suppose, to the contrary, that the optimal price distribution $F$ puts positive 
weight on more than one atom in $\left(p_{z}, p_{z^{*}}\right]$. Consider a new pricing distribution $F^{\prime}$ constructed from $F$ by replacing the original prices $p_{z+1}$ through $p_{z^{*}}$ with the average price $p_{a}=\left(\sum_{l=z+1}^{z^{*}} p_{l} q_{l}\right) /\left(\sum_{l=z+1}^{z^{*}} q_{l}\right)$, and putting the rest of the weight on a single atom $p_{a+1}$ above $\bar{p}=(1+\eta \lambda) /(1+\eta)$. Define $Q_{a}$ and $P_{a}$ analogously to the notation above. Then, by construction, $Q_{z^{*}}=Q_{a}$ and $Q_{z^{*}} P_{z^{*}}=Q_{a} P_{a}$. Using that for the market price distribution $F, p_{z^{*}}$ satisfies (4), one has

$$
p_{a}<p_{z^{*}} \leq \frac{1+\eta\left(1-Q_{z^{*}}\right)+\eta \lambda Q_{z^{*}}}{1+\eta \lambda} v+\frac{\eta(\lambda-1)}{1+\eta \lambda} Q_{z^{*}} P_{z^{*}} \leq p_{z^{*}+1},
$$

and since $p_{a}<p_{z^{*}}$, this implies

$$
p_{a}<\frac{1+\eta\left(1-Q_{a}\right)+\eta \lambda Q_{a}}{1+\eta \lambda} v+\frac{\eta(\lambda-1)}{1+\eta \lambda} Q_{a} P_{a}<p_{a+1} .
$$

Hence, when facing the price distribution $F^{\prime}$ buying up to the price $p_{a}$ is a personal equilibrium. Furthermore, it is easy to show using (3) that $E U\left(p_{z^{*}} ; F\right)<E U\left(p_{a} ; F^{\prime}\right)$ and by construction, $E U\left(p_{l} ; F\right)=E U\left(p_{l} ; F^{\prime}\right)$ for any $l<z^{*}$. Thus buying for any price less than or equal to $p_{a}$ is the PPE strategy of the consumer when facing $F^{\prime}$. Continuity of both ex ante and ex post utility with respect to $p_{a}$ implies that if the monopolist increases $p_{a}$ slightly, the PPE still involves the consumer buying for all prices less than or equal to $p_{a}$. This increases profits, a contradiction.

A(ii). Second, we show by contradiction that $Q_{z^{*}}=1$. Suppose $Q_{z^{*}}<1$. If the monopolist can profitably sell to the consumer, it must make a profit at the highest price $p_{z^{*}}$ at which the consumer buys in PPE. Now consider the distribution $F^{\prime}$ constructed from $F$ by moving the probability weight $1-Q_{z^{*}}$ from the prices above $p_{z^{*}}$ to $p_{z^{*}}$. We show that the consumer buys for all prices in the PPE for $F^{\prime}$ and, hence, this change increases profits, yielding a contradiction. If $z=z^{*}$, it follows from (4) that buying at all prices is the unique PE with $F^{\prime}$. If $z^{*}>z$, the above implies that $z^{*}=z+1$. In addition, it follows from (4) that buying at all prices is a PE after the price change. Now using (3) and the fact that with price distribution $F$ the consumer prefers the PE in which she buys up to $p_{z^{*}}$, one has

$$
\begin{aligned}
& E U\left(p_{z} ; F\right)=Q_{z} v-Q_{z} P_{z}-\eta(\lambda-1) Q_{z}\left(1-Q_{z}\right) v \\
& -\eta(\lambda-1) Q_{z}\left(1-Q_{z}\right) P_{z}-\eta(\lambda-1) \sum_{l^{\prime}=1}^{z} \sum_{l^{\prime \prime}=1}^{l^{\prime}} q_{l^{\prime \prime}} q_{l^{\prime}}\left(p_{l^{\prime}}-p_{l^{\prime \prime}}\right) \\
& \leq Q_{z} v-Q_{z} P_{z}+q_{z^{*}}\left(v-p_{z^{*}}\right)-\eta(\lambda-1)\left(Q_{z}+q_{z^{*}}\right)\left(1-Q_{z}-q_{z^{*}}\right) v \\
& -\eta(\lambda-1)\left(1-Q_{z}-q_{z^{*}}\right)\left(Q_{z} P_{z}+q_{z^{*}} p_{z^{*}}\right) \\
& -\eta(\lambda-1)\left(\sum_{l^{\prime}=1}^{z} \sum_{l^{\prime \prime}=1}^{l^{\prime}} q_{l^{\prime \prime}} q_{l^{\prime}}\left(p_{l^{\prime}}-p_{l^{\prime \prime}}\right)+q_{z^{*}} \sum_{l=1}^{z^{*}} q_{l}\left(p_{z^{*}}-p_{l}\right)\right) \\
& =E U\left(p_{z^{*}} ; F\right) \text {. }
\end{aligned}
$$


Rewriting using that

$$
q_{z^{*}} \sum_{l=1}^{z^{*}} q_{l}\left(p_{z^{*}}-p_{l}\right)=q_{z^{*}}\left(Q_{z} p_{z^{*}}-Q_{z} P_{z}\right),
$$

gives

$$
0 \leq q_{z^{*}}\left(v-p_{z^{*}}\right)-\eta(\lambda-1)\left(\left(q_{z^{*}}\left(1-Q_{z}\right)-q_{z^{*}} Q_{z}-q_{z^{*}}^{2}\right) v+\left(1-q_{z^{*}}\right) q_{z^{*}} p_{z^{*}}-2 q_{z^{*}} Q_{z} P_{z}\right) .
$$

Dividing by $q_{z^{*}}$, one has

$$
0 \leq v-p_{z^{*}}-\eta(\lambda-1)\left(\left(1-2 Q_{z}-q_{z^{*}}\right) v+\left(1-q_{z^{*}}\right) p_{z^{*}}-2 Q_{z} P_{z}\right) .
$$

As the right-hand side is increasing in $q_{z^{*}}$ and we construct $F^{\prime}$ by moving the probability weight $1-Q_{z^{*}}$ from the prices above $p_{z^{*}}$ to $p_{z^{*}}$, which increases $q_{z^{*}}$, it follows that $E U\left(p_{z} ; F^{\prime}\right) \leq E U\left(p_{z^{*}} ; F^{\prime}\right)$. This completes the proof that $Q_{z^{*}}=1$.

Summarizing, so far we have shown that the optimal price distribution has the following structure. The monopolist charges the prices $p_{1}$ through $p_{z}$ with a total probability of $Q_{z}$ and charges the price $p_{z^{*}}$ with probability $1-Q_{z}$, where either $z^{*}=z$ or $z^{*}=z+1$. In addition, if $z^{*}=z$, there is exactly one $\mathrm{PE}$, and if $z^{*}=z+1$, there are exactly two PE: one in which the consumer buys up to price $p_{z}$, and one in which she buys at all prices. Finally, in the PPE, the consumer buys at all prices. Our next goal is to show that in the optimal price distribution, we have $0<Q_{z}<1$, so that $z^{*}=z+1$ and $z>0$. We establish this by showing that the monopolist can earn greater revenue with $z^{*}=z+1$ and $z>0$ than with either $z=0$ or $z^{*}=z$.

$\mathrm{A}(\mathrm{iii})$. First consider $z=0$. In that case, the monopolist charges a single deterministic price. Note that in any PE, the consumer gets what she expected, so that her total utility is equal to her consumption utility. ${ }^{23}$ This means that for any $p>v$, the ex ante optimal strategy is not to buy. We show that for such prices, not buying is a PE, so that it must be the PPE. Suppose that the consumer had expected not to buy the product. If she buys, her consumption utility is $v-p$ and her gain-loss utility-consisting of a gain of $v$ in the product and a loss of $p$ in money-is $\eta v-\eta \lambda p$. If she does not buy, both her consumption utility and (as her outcomes conform to her expectations) her gain-loss utility are zero. Hence, she is willing to follow a plan not to buy, and therefore not buying is a $\mathrm{PE}$, if and only if

$$
p>\frac{1+\eta}{1+\eta \lambda} \cdot v \equiv \underline{p} .
$$

Since this inequality is satisfied for any $p>v$, at these prices it is a PE for the consumer not to buy.

A(iv). We now establish that if $\Delta<v-p$, the firm charges at least two prices with positive probability, so that $z>0$. Recall that the optimal deterministic price is $v$. To prove that the firm charges at least two prices with positive probability, we construct a

\footnotetext{
${ }^{23}$ In the current setting, there is no mixed-strategy PE because we have assumed that whenever the consumer is indifferent between buying and not buying, she buys with probability 1 .
} 
hybrid distribution with which the monopolist earns expected revenue greater than $v$. Consider the distribution that puts weight $\epsilon>0$ on $\underline{p}$ and weight $1-\epsilon$ on

$$
p_{z^{*}}=v+\frac{2 \eta(\lambda-1) \epsilon \underline{p}}{1+\eta(\lambda-1) \epsilon} .
$$

It is easy to check (either directly or using (6) below) that for a sufficiently small $\epsilon$ buying at both prices is the PPE. Hence, with this pricing distribution the firm's revenue is

$$
(1-\epsilon) v+(1-\epsilon) \frac{2 \eta(\lambda-1)}{1+\eta(\lambda-1) \epsilon} \epsilon \underline{p}+\epsilon \underline{p} .
$$

For $\epsilon=0$ the revenue is equal to $v$. Taking the derivative with respect to $\epsilon$ and evaluating it at $\epsilon=0$ yields

$$
-v+\underline{p}(2 \eta(\lambda-1)+1)=\frac{\eta(\lambda-1)+2 \eta^{2}(\lambda-1)}{1+\eta \lambda} \cdot v>0 .
$$

$\mathrm{A}(\mathrm{v})$. Note that if $z^{*}=z+1$, then for the consumer to be willing to buy at all prices, it must both be a PE to buy up to price $p_{z^{*}}$, and this strategy must be preferred to the PE of buying only up to price $p_{z}$. By (4) and (5), the highest $p_{z^{*}}$ at which this holds is

$$
p_{z^{*}}=\min \left\{\frac{v+(\eta(\lambda-1) /(1+\eta \lambda)) Q_{z} P_{z}}{1-(\eta(\lambda-1) /(1+\eta \lambda)) q_{z^{*}}}, v+\frac{2 \eta(\lambda-1) Q_{z} P_{z}}{1+\eta(\lambda-1) Q_{z}}\right\} .
$$

Notice that holding $Q_{z}$ fixed (which also fixes $q_{z^{*}}=1-Q_{z}$ ), $p_{z^{*}}$ is increasing in $Q_{z} P_{z}$. Hence, whether $z^{*}=z$ or $z^{*}=z+1$, to maximize profits the monopolist must maximize $Q_{z} P_{z}$ subject to the constraint that the consumer buys with probability $Q_{z}$ in any PE. We next consider the implications of this maximization problem.

Notice that for any price $p_{l}<p_{z}$ on the support of the distribution, we show by contradiction that it is optimal to charge $p_{l}$ with the lowest possible probability such that the consumer is just willing to buy at the next price if she had been expecting to buy at prices up to $p_{l}$. Suppose this is not the case, and consider shifting a little bit of weight from $p_{l}$ to $p_{l+1}$. For a sufficiently small shifted weight (4) implies that it will still be the case that in any $\mathrm{PE}$ the consumer buys at all prices up to $p_{z}$.

We now solve for the weight the monopolist must put on each price for the above property to hold for all $l<z$. That the consumer is just willing to buy at price $p_{l}$ if she had been expecting to buy at prices up to $p_{l-1}$ is equivalent to

$$
v-p_{l}+\eta\left(1-Q_{l-1}\right) v-\eta \lambda\left(1-Q_{l-1}\right) p_{l}-\eta \lambda Q_{l-1}\left(p_{l}-P_{l-1}\right)=-\eta \lambda Q_{l-1} v+\eta Q_{l-1} P_{l-1}
$$

or

$$
\left(1+\eta+\eta(\lambda-1) Q_{l-1}\right) v-(1+\eta \lambda) p_{l}+\eta(\lambda-1) Q_{l-1} P_{l-1}=0 .
$$

The corresponding equation for the consumer to just be willing to buy at price $p_{l+1}$ is

$$
\left(1+\eta+\eta(\lambda-1) Q_{l}\right) v-(1+\eta \lambda) p_{l+1}+\eta(\lambda-1) Q_{l} P_{l}=0 .
$$


Subtracting the latter equation from the former one and rearranging yields

$$
q_{l}=\frac{(1+\eta \lambda)\left(p_{l+1}-p_{l}\right)}{\eta(\lambda-1)\left(v+p_{l}\right)}=\frac{A\left(p_{l+1}-p_{l}\right)}{v+p_{l}} .
$$

This completes the claim in the proposition regarding the weights $q_{l}$ for $l<z$.

Next, we establish that $\operatorname{Pr}_{F}\left(p_{z}\right)<2 A \Delta /\left(v+p_{z}\right)$. Suppose, to the contrary, that $\operatorname{Pr}_{F}\left(p_{z}\right) \geq 2 A \Delta /\left(v+p_{z}\right)$. Then, if the monopolist set $p_{z^{*}}=p_{z}+2 \Delta$, it would be a unique PE for the consumer to buy at all prices. Hence, the optimal price distribution must have $p_{z^{*}}>p_{z}+2 \Delta$. Hence, the monopolist could construct a new distribution $F^{\prime}$ from $F$ in the following way. Let $z^{\prime}=z+1$ and $z^{* \prime}=z^{*}+1$, with the distribution $F^{\prime}$ created from $F$ by shifting the weight $\operatorname{Pr}_{F}\left(p_{z}\right)-A \Delta /\left(v+p_{z}\right)$ upward from $p_{z}$ to $p_{z+1}=p_{z}+\Delta$. Then, by the above calculation, with $F^{\prime}$ the consumer buys up to $p_{z+1}$ in any PE. Since $Q_{z^{\prime}}^{\prime} P_{z^{\prime}}^{\prime}>Q_{z} P_{z}$, this contradicts that $Q_{z} P_{z}$ maximizes profits subject to the constraint that the consumer buys with probability $Q_{z}$ in any PE.

Now we show that up to $p_{z}$, the atoms of the optimal price distribution are spaced at intervals of less than $2 \Delta$. Suppose, to the contrary, that this is not the case for the optimal price distribution $F$, so that for some $l \leq z-1, p_{l+1}-p_{l} \geq 2 \Delta$. We construct the distribution $F^{\prime}$ from $F$ in the following way. We let $z^{\prime}=z+1$ and $z^{* \prime}=z^{*}+1$, we put an extra atom at $p_{l}+\Delta$, and let $q_{l}^{\prime}=A \Delta /\left(v+p_{l}\right)$ and $q_{l+1}^{\prime}=q_{l}-A \Delta /\left(v+p_{l}\right)$, with the weights and positions of the other atoms remaining the same. Since $q_{l+1}^{\prime}=A\left(p_{l+2}^{\prime}-p_{l+1}^{\prime}\right) /\left(v+p_{l}\right)>$ $A\left(p_{l+2}^{\prime}-p_{l+1}^{\prime}\right) /\left(v+p_{l+1}^{\prime}\right)$, this maintains the property that in any PE, the consumer buys at all prices up to $p_{z}\left(=p_{z+1}^{\prime}\right)$; and since $Q_{z^{\prime}}^{\prime} P_{z^{\prime}}^{\prime}>Q_{z} P_{z}$, this contradicts that $Q_{z} P_{z}$ maximizes profits subject to the constraint that the consumer buys with probability $Q_{z}$ in any PE.

Next we show that $\underline{p}-2 \Delta<p_{1} \leq \underline{p}$. Clearly, if $p_{1}>\underline{p}$, there is a PE in which the consumer does not buy. We are left to show that $p_{1}>p-\overline{2 \Delta}$. Suppose otherwise. Then, since $p_{2}-p_{1}<2 \Delta$, we must have $p_{2}<\underline{p}$. Now we construct the price distribution $F^{\prime}$ from $F$ by moving the atom at $p_{1}$ to $p_{2}$. This ensures that the consumer buys for all prices up to $p_{z}$ in any $\mathrm{PE}$ and has $Q_{z^{\prime}}^{\prime} P_{z^{\prime}}^{\prime}>Q_{z} P_{z}$, a contradiction.

A(vi). We are thus left to rule out that $Q_{z}=1$. Suppose, toward a contradiction, that for an optimal price distribution $F, Q_{z}=1$. By A(iv), $\sum_{l=1}^{z} q_{l} p_{l}>v$, and hence $p_{z}>v$. By $\mathrm{A}(\mathrm{v}), p_{z}$ is such that if the consumer expected to buy at prices up to $p_{z-1}$, she would just be indifferent between buying and not buying at $p_{z}$. Using (4), this means

$$
p_{z}=\frac{1+\eta\left(1-Q_{z-1}\right)+\eta \lambda Q_{z-1}}{1+\eta \lambda} v+\frac{\eta(\lambda-1)}{1+\eta \lambda} Q_{z-1} P_{z-1} .
$$

Notice that the above implies

$$
p_{z}<\frac{1+\eta\left(1-Q_{z}\right)+\eta \lambda Q_{z}}{1+\eta \lambda} v+\frac{\eta(\lambda-1)}{1+\eta \lambda} Q_{z} P_{z}=v+\frac{\eta(\lambda-1)}{1+\eta \lambda} P_{z} .
$$

Now consider a price distribution $F^{\prime}$ obtained from $F$ by moving the atom at $p_{z}$ to some $p_{z}^{\prime}>p_{z}$, while leaving all other atoms and all weights unchanged. By continuity of both sides in $p_{z}^{\prime}$, the above inequality implies that for $p_{z}^{\prime}$ sufficiently close to $p_{z}$, it is a PE for 
the consumer to buy at all prices when facing $F^{\prime}$. We now show that for $p_{z}^{\prime}$ sufficiently close to $p_{z}$, when facing $F^{\prime}$ the consumer prefers the PE of buying at all prices to the PE of buying only up to price $p_{z-1}$, so that always buying is the PPE. This completes the proof because $F^{\prime}$ yields higher revenue than $F$, contradicting the optimality of $F$.

Using (3), we want to show that

$$
\begin{aligned}
v- & P_{z}^{\prime}-\eta(\lambda-1) \sum_{l^{\prime}=1}^{z} \sum_{l^{\prime \prime}=1}^{l^{\prime}} q_{l^{\prime \prime}} q_{l^{\prime}}\left(p_{l^{\prime}}^{\prime}-p_{l^{\prime \prime}}^{\prime}\right) \\
>Q_{z-1} v-Q_{z-1} P_{z-1}-\eta(\lambda-1) Q_{z-1}\left(1-Q_{z-1}\right)\left(v+P_{z-1}\right) & -\eta(\lambda-1) \sum_{l^{\prime}=1}^{z-1} \sum_{l^{\prime \prime}=1}^{l^{\prime}} q_{l^{\prime \prime}} q_{l^{\prime}}\left(p_{l^{\prime}}^{\prime}-p_{l^{\prime \prime}}^{\prime}\right) .
\end{aligned}
$$

Rearranging, this is equivalent to

$$
q_{z} v-q_{z} p_{z}^{\prime}+\eta(\lambda-1) q_{z}\left(1-q_{z}\right)\left(v+P_{z-1}\right)-\eta(\lambda-1) q_{z}\left(\sum_{l^{\prime \prime}=1}^{z} q_{l^{\prime \prime}}\left(p_{z}^{\prime}-p_{l^{\prime \prime}}^{\prime}\right)\right)>0
$$

which, using that $p_{l^{\prime \prime}}^{\prime}=p_{l^{\prime \prime}}$ for $l^{\prime \prime}<z$ and therefore $\sum_{l^{\prime \prime}=1}^{z-1} q_{l^{\prime \prime}} p_{l^{\prime \prime}}^{\prime}=Q_{z-1} P_{z-1}$, simplifies to

$$
p_{z}^{\prime}<v+\frac{2 \eta(\lambda-1)}{1+\eta(\lambda-1) Q_{z-1}} Q_{z-1} P_{z-1} .
$$

Because the right-hand side of this inequality is strictly greater than the right-hand side of (7), this inequality must hold for $p_{z}^{\prime}$ sufficiently close to $p_{z}$.

Part B. Suppose, to the contrary, that a profit-maximizing pricing distribution does not exist. Then since the firm's profits are bounded, there must be a sequence of price distributions $F^{n}$ such that the corresponding profits converge to the supremum profit level $\pi^{*}$. By the logic of Part A, for any pricing distribution there is a corresponding pricing distribution with at least as high profits that satisfies the properties of the proposition, and for which the highest price is given by (6). Hence, we can choose $F^{n}$ so that it satisfies these properties.

Define $z^{n}$ and $z^{n *}$ for each $F^{n}$ as above. Since pricing atoms must be at least $\Delta$ apart and since the consumer does not buy for any price above $\bar{p}, z^{n}$ and $z^{n *}$ both come from a finite set. Therefore, $F^{n}$ must have a subsequence for which $z^{n}$ and $z^{n *}$ are constant. With slight abuse of notation, we assume that $F^{n}$ already has this property. Then, by the diagonal method, it is easy to show that $F^{n}$ has a subsequence in which the locations of all atoms and all their weights converge. With another slight abuse of notation, we assume that $F^{n}$ already has this property.

Now consider the limiting distribution of the sequence $F^{n}, F$. By construction, in any $\mathrm{PE}$ the consumer buys for any price up to $p_{z}$. In addition, by (6), which is continuous in $p_{l}$ and $q_{l}$, in PPE the consumer is willing to buy also at $p_{z^{*}}$. Hence, when facing $F$, the PPE is for the consumer to buy at all prices, so that the firm achieves profit level $\pi^{*}-$ a contradiction. 


\section{Appendix C: Proofs of PROPOSITIONS IN TEXT}

Proof of Proposition 1. Consider a sequence $\Delta^{n} \rightarrow 0$ such that a sequence of corresponding optimal pricing distributions $F^{n}$ converges in distribution. Define $z^{n}, p_{l}^{n}, q_{l}^{n}$, and $Q_{z^{n}}^{n}$ analogously to Proposition 4 . Assume first that $Q_{z^{n}}^{n}$ converges to some $s$; we establish this below.

Trivially, as $\Delta$ decreases, the optimal profits must weakly increase, since the firm could always choose the same distribution as it did for a higher value of $\Delta$. Also, the profits the monopolist can earn are bounded, so that there is a limiting profit strictly greater than $v$. By the proof of Proposition 4 , if we had $s=0$, then the limiting profit would be $v$, and if we had $s=1$, the limiting profits would be less than $v$. Hence, we can conclude that $0<s<1$.

As in Proposition 4, consider the distribution on $\left[\underline{p}, p_{\max }\right]$ with density

$$
h(p)=\frac{1+\eta \lambda}{\eta(\lambda-1)(v+p)}=\frac{A}{v+p} .
$$

Let the corresponding cumulative distribution function be $H$ and define $p_{\max }(s)$ so that $H\left(p_{\max }(s)\right)=s$. We now establish that for $x \leq p_{\max }(s), F^{n}(x) \rightarrow H(x)$ as $n \rightarrow \infty$; that is, in that part of the real line, $F^{n}$ converges in distribution $H$.

Since $\underline{p}-2 \Delta^{n}<p_{1}^{n} \leq \underline{p}$, we have $p_{1}^{n} \rightarrow \underline{p}$. We prove that $p_{z^{n}}^{n} \rightarrow p_{\max }(s)$. We have

$$
\begin{aligned}
Q_{z^{n}}^{n} & =\sum_{l=1}^{z^{n}} q_{l}^{n}=q_{z^{n}}^{n}+A \sum_{l=1}^{z^{n}-1} \frac{p_{l+1}^{n}-p_{l}^{n}}{v+p_{l}^{n}} \\
& =q_{z^{n}}^{n}+A \sum_{l=1}^{z^{n}-1}[\int_{p_{l}^{n}}^{p_{l+1}^{n}} \frac{1}{v+p} d p+\underbrace{\int_{p_{l}^{n}}^{p_{l+1}^{n}}\left(\frac{1}{v+p_{l}^{n}}-\frac{1}{v+p}\right) d p} .
\end{aligned}
$$

We work on the sum of the underbraced term:

$$
\sum_{l=1}^{z^{n}-1} \int_{p_{l}^{n}}^{p_{l+1}^{n}}\left(\frac{1}{v+p_{l}^{n}}-\frac{1}{v+p}\right) d p=\sum_{l=1}^{z^{n}-1} \int_{p_{l}^{n}}^{p_{l+1}^{n}} \frac{p-p_{l}^{n}}{\left(v+p_{l}^{n}\right)(v+p)} d p .
$$

Notice that this is positive and (since $p_{l+1}^{n}-p_{l}^{n}<2 \Delta^{n}$ ) it is less than

$$
\sum_{l=1}^{z^{n}-1} \int_{p_{l}^{n}}^{p_{l+1}^{n}} \frac{2 \Delta^{n}}{\left(v+p_{l}^{n}\right)(v+p)} d p<\sum_{l=1}^{z^{n}-1} \frac{2\left(p_{l+1}^{n}-p_{l}^{n}\right) \Delta^{n}}{v^{2}}=\frac{2\left(p_{z^{n}}^{n}-p_{1}^{n}\right) \Delta^{n}}{v^{2}},
$$

which approaches zero as $n \rightarrow \infty$. Taking the limit of (8), plugging in that the sum of the underbraced terms approaches zero, and using that $q_{z^{n}}^{n} \rightarrow 0$ as $n \rightarrow \infty$, we get

$$
s=\lim _{n \rightarrow \infty} A \int_{p_{1}^{n}}^{p_{z^{n}}^{n}} \frac{1}{v+p} d p=\lim _{n \rightarrow \infty} A \int_{\underline{p}}^{p_{z^{n}}^{n}} \frac{1}{v+p} d p .
$$

This implies that $p_{z^{n}}^{n} \rightarrow p_{\max }(s)$ as $n \rightarrow \infty$. 
Next, we show that for a sufficiently large $n$, we have $p_{z^{n}+1}^{n}>p_{\max }(s)$. We know that $p_{z_{n}}^{n}$ satisfies the condition that if the consumer expected to buy up to price $p_{z^{n}-1}^{n}$, she would just be indifferent to buying at $p_{z^{n}}^{n}$. This is equivalent to

$$
\begin{aligned}
p_{z^{n}}^{n} & =\frac{\left(1+\eta+\eta(\lambda-1) Q_{z^{n}-1}^{n}\right) v+\eta(\lambda-1) Q_{z^{n}-1}^{n} P_{z^{n}-1}^{n}}{1+\eta \lambda} \\
& \leq \frac{\left(1+\eta+\eta(\lambda-1) Q_{z^{n}}^{n}\right) v+\eta(\lambda-1) Q_{z^{n}}^{n} P_{z^{n}}^{n}}{1+\eta \lambda} .
\end{aligned}
$$

Given that $p_{z^{n}}^{n} \rightarrow p_{\max }(s)$ and $Q_{z^{n}}^{n} \rightarrow s<1$, this and (6) imply that for a sufficiently large $n$, we have $p_{z^{n}+1}^{n}>p_{\max }(s)$.

Clearly, for any $x \leq \underline{p}, H(x)=\lim _{n \rightarrow \infty} F^{n}(x)=0$. Now take any $x$ satisfying $\underline{p}<x<$ $p_{\max }(s)$. As long as $p_{z^{n}}^{n}>x$, which holds for $n$ sufficiently large, we have

$$
\begin{aligned}
F^{n}(x) & =\sum_{l, p_{l}^{n} \leq x} q_{l}^{n}=A \sum_{l, p_{l}^{n} \leq x} \frac{p_{l+1}^{n}-p_{l}^{n}}{v+p_{l}^{n}} \\
& =A \sum_{l, p_{l}^{n} \leq x}[\int_{p_{l}^{n}}^{p_{l+1}^{n}} \frac{1}{v+p} d p+\underbrace{\left.\int_{p_{l}^{n}}^{p_{l+1}^{n}}\left(\frac{1}{v+p_{l}^{n}}-\frac{1}{v+p}\right) d p\right] .} .
\end{aligned}
$$

By the same argument as above, the sum of the underbraced term approaches zero as $n \rightarrow \infty$ and we must have $\max _{l}\left\{p_{l}^{n} \mid p_{l}^{n} \leq x\right\} \rightarrow x$ as $n \rightarrow \infty$. Hence, taking the limit of (9), we have

$$
\lim _{n \rightarrow \infty} F^{n}(x)=A \int_{\underline{p}}^{x} \frac{1}{v+p} d p=H(x) .
$$

Finally, since for $n$ sufficiently large $p_{z^{n}+1}^{n}>p_{\max }(s), \lim _{n \rightarrow \infty} \operatorname{Pr}_{F^{n}}\left(p_{\max }(s)\right)=0$. This completes the proof that for $x \leq p_{\max }(s), F^{n}(x) \rightarrow H(x)$ as $n \rightarrow \infty$.

Next, notice that for $F^{n}$ to converge in distribution, the sequence $p_{z^{n}+1}$ must converge. Let the limit be $p$. Applying (6), $p>p_{\max }(s)$. We have shown that the limiting distribution has the properties in the proposition.

To conclude the proof, it remains to show that $Q_{z^{n}}^{n}$ converges. Suppose, to the contrary, that it does not. Then the sequence $F^{n}$ must have two subsequences $F^{n_{1}}$ and $F^{n_{2}}$ such that $Q_{z^{n_{1}}}^{n_{1}}$ and $Q_{z^{n_{2}}}^{n_{2}}$ both converge, but to different limits $s_{1}$ and $s_{2}$, respectively. Then the above arguments imply that $F^{n_{1}}$ and $F^{n_{2}}$ converge in distribution to different distributions: the limit of $F^{n_{1}}$ is distributed continuously on [ $\left.p, p_{\max }\left(s_{1}\right)\right]$ and has an isolated atom, while the limit of $F^{n_{2}}$ is distributed continuously on $\left[\underline{p}, p_{\max }\left(s_{2}\right)\right]$ and has an isolated atom. But this means that the sequence $F^{n}$ does not converge in distribution, a contradiction.

Proof of Proposition 2. From the proof of Proposition 4, for $\Delta<v-p$ the consumer buys the product with probability 1 at an expected price strictly greater than $v$. Hence, her consumption utility is negative. Furthermore, in any PE expected gain-loss utility is nonpositive. If she follows through a plan of never buying, both her consumption utility and her gain-loss utility are zero. 
Proof of Proposition 3. We first show that firms earn zero expected profits in equilibrium. Suppose otherwise. Then we can assume without loss of generality that firm 1 earns weakly lower profits than firm 2, so that firm 2 earns positive expected profit. To make positive expected profit, firm 2 must attract the consumer with positive probability. Let $F_{2}$ be firm 2's price distribution, with price atoms $p_{1}^{2}, \ldots, p_{S}^{2}$ and weight $q_{s}^{2}$ on $p_{s}^{2}$. Similarly to above, let $p_{z}^{2}$ be the highest price at which the consumer buys in any PE and let $p_{z^{*}}^{2}$ be the highest price at which she buys with positive probability. We distinguish two cases.

First, suppose $p_{z^{*}}^{2}=p_{z}^{2}$. Then consider the price distribution $F_{1}$ obtained from $F_{2}$ by shifting all prices up to $p_{z}^{2}$ down by $\epsilon>0$ and putting the rest of the weight on any price strictly greater than $(1+\eta \lambda) v /(1+\eta)$. Then the consumer's unique PE when facing price distribution $F_{1}$ is to buy up to the price $p_{z}^{2}-\epsilon$. In addition, the consumer's ex ante expected utility is strictly higher under $F_{1}$ than under $F_{2}$, so that firm 1 attracts the consumer with probability 1 . For a sufficiently small $\epsilon>0$, this deviation therefore increases firm 1's expected profits, contradicting equilibrium.

Second, suppose that $p_{z^{*}}^{2}>p_{z}^{2}$. Consider the price distribution $F_{1}$ obtained from $F_{2}$ by (i) keeping the prices and weights up to $p_{z}^{2}$ the same; (ii) replacing the prices $p_{z+1}^{2}, \ldots, p_{z^{*}}^{2}$ with a single atom at the average $p_{z+1}^{1}=\left(q_{z+1}^{2} p_{z+1}^{2}+\cdots+q_{z^{*}}^{2} p_{z^{*}}^{2}\right) /$ $\left(q_{z+1}^{2}+\cdots+q_{z^{*}}^{2}\right)-\epsilon$; (iii) putting the rest of the weight on any price strictly greater than $(1+\eta \lambda) v /(1+\eta)$. The consumer's unique PPE when facing the price distribution $F_{1}$ is to buy up to the price $p_{z+1}^{1}$, and in this PPE the consumer obtains ex ante expected utility strictly greater than that when facing $F_{2}$. Hence, firm 1 attracts the consumer with probability 1 . For a sufficiently small $\epsilon>0$, this deviation therefore increases firm 1's expected profits, contradicting equilibrium. This completes the proof that firms earn zero expected profits in equilibrium.

To complete the proof, we show that firms charge a deterministic price of $c$ in equilibrium. Observe that if the consumer goes to a firm that makes zero expected profits, the consumer's ex ante expected utility is weakly lower than $v-c$ : the consumer's expected consumption utility is at most $v-c$, and by (3) her gain-loss utility is nonpositive. Furthermore, if the consumer faces a stochastic price, by the same logic (and using that in that case she faces uncertainty either in the product or in the price dimension) her ex ante expected utility is strictly lower than $v-c$.

Now suppose, toward a contradiction, that firm 2 charges a (nondegenerate) stochastic price. Then the consumer cannot strictly prefer firm 1 to firm 2: if this were the case, then by the above observation the ex ante expected utility the consumer would obtain from firm 2 would be strictly lower than $v-c$; but in that case, firm 1 could make positive profits by offering a deterministic price of $c+\epsilon$ for a sufficiently small $\epsilon>0$. Because the consumer does not strictly prefer firm 1, the consumer visits firm 2 with positive probability. Again by the above observation, then firm 2 gives the consumer an ex ante expected utility strictly below $v-c$. Hence, once again firm 1 has a profitable deviation, a contradiction. 


\section{REFERENCES}

Abeler, Johannes, Armin Falk, Lorenz Götte, and David Huffman (2011), "Reference points and effort provision.” American Economic Review, 101, 470-492. [234]

Anderson, Eric T. and Duncan I. Simester (2010), "Price stickiness and customer antagonism.” Quarterly Journal of Economics, 125, 729-765. [236]

Barberis, Nicholas, Ming Huang, and Tano Santos (2001), "Prospect theory and asset prices." Quarterly Journal of Economics, 116, 1-53. [218]

Barberis, Nick, Ming Huang, and Richard H. Thaler (2006), "Individual preferences, monetary gambles, and stock market participation: A case of narrow framing." American Economic Review, 96, 1069-1090. [234]

Baye, Michael R., Dan Kovenock, and Casper G. de Vries (1992), "It takes two to tango: Equilibria in a model of sales." Games and Economic Behavior, 4, 493-510. [235]

Benartzi, Shlomo and Richard H. Thaler (1995), "Myopic loss aversion and the equity premium puzzle.” Quarterly Journal of Economics, 110, 73-92. [218]

Bils, Mark and Peter J. Klenow (2004), "Some evidence on the importance of sticky prices.” Journal of Political Economy, 112, 947-985. [222]

Camerer, Colin F., Linda Babcock, George Loewenstein, and Richard H. Thaler (1997), "Labor supply of New York City cabdrivers: One day at a time." Quarterly Journal of Economics, 112, 407-441. [234]

Caplin, Andrew and John Leahy (2001), "Psychological expected utility and anticipatory feelings.” Quarterly Journal of Economics, 116, 55-79. [228]

Cecchetti, Stephen G. (1986), “The frequency of price adjustment: A study of the newsstand prices of magazines." Journal of Econometrics, 31, 255-274. [222, 223]

Chevalier, Judith A., Anil K. Kashyap, and Peter E. Rossi (2003), "Why don't prices rise during periods of peak demand? Evidence from scanner data." American Economic Review, 93, 15-37. [222]

Conlisk, John, Eitan Gerstner, and Joel Sobel (1984), "Cyclic pricing by a durable goods monopolist.” Quarterly Journal of Economics, 99, 489-505. [235]

Crawford, Vincent P. and Juanjuan Meng (2011), "New York City cabdrivers' labor supply revisited: Reference-dependent preferences with rational-expectations targets for hours and income." American Economic Review, 101, 1912-1932. [234]

Davidson, Carl and Raymond Deneckere (1986), "Long-run competition in capacity, short-run competition in price, and the Cournot model." RAND Journal of Economics, 17, 404-415. [235]

Eichenbaum, Martin, Nir Jaimovich, and Sergio Rebelo (2009), "Reference prices, costs and nominal rigidities." Unpublished paper. [222, 223] 
Einav, Liran and Barak Y. Orbach (2007), "Uniform prices for differentiated goods: The case of the movie-theater industry." International Review of Law and Economics, 27, 129-153. [223]

Erickson, Gary M. and Johny K. Johansson (1985), “The role of price in multi-attribute product evaluations.” Journal of Consumer Research, 12, 195-199. [234]

Ericson, Keith M. Marzilli and Andreas Fuster (2011), "Expectations as endowments: Evidence on reference-dependent preferences from exchange and valuation experiments." Quarterly Journal of Economics, 126, 1879-1907. [234]

Farber, Henry S. (2005), "Is tomorrow another day? The labor supply of New York City cabdrivers.” Journal of Political Economy, 113, 46-82. [234]

Farber, Henry S. (2008), "Reference-dependent preferences and labor supply: The case of New York City taxi drivers.” American Economic Review, 98, 1069-1082. [234]

Fudenberg, Drew and David K. Levine (1989), "Reputation and equilibrium selection in games with a patient player.” Econometrica, 57, 759-778. [223]

Gal-Or, Esther (1982), “Hotelling's spatial competition as a model of sales.” Economics Letters, 9, 1-6. [235]

Hardie, Bruce G. S., Eric J. Johnson, and Peter S. Fader (1993), "Modeling loss aversion and reference dependence effects on brand choice." Marketing Science, 12, 378-394. [234]

Heidhues, Paul and Botond Kőszegi (2005), “The impact of consumer loss aversion on pricing.” Discussion Paper 4849, Centre for Economic Policy Research. [235]

Heidhues, Paul and Botond Kőszegi (2008), “Competition and price variation when consumers are loss averse.” American Economic Review, 98, 1245-1268. [218, 223, 232, 235]

Heidhues, Paul and Botond Kőszegi (2011), “Regular prices and sales.” Unpublished paper. [231, 232, 233]

Herweg, Fabian and Konrad Mierendorff (2013), "Uncertain demand, consumer loss aversion, and flat-rate tariffs." Journal of the European Economic Association, 11, 399-432. [218, 235]

Herweg, Fabian, Daniel Müller, and Philipp Weinschenk (2010), "Binary payment schemes: Moral hazard and loss aversion.” American Economic Review, 100, 2451-2477. $[218,235]$

Jacobson, Robert and Carl Obermiller (1990), "The formation of expected future price: A reference price for forward-looking consumers." Journal of Consumer Research, 16, 420-432. [234]

Kahneman, Daniel, Jack L. Knetsch, and Richard H. Thaler (1990), "Experimental tests of the endowment effect and the Coase theorem." Journal of Political Economy, 98, 1325-1348. [220, 234] 
Kahneman, Daniel, Jack L. Knetsch, and Richard H. Thaler (1991), "Anomalies: The endowment effect, loss aversion, and status quo bias." Journal of Economic Perspectives, 5 (1), 193-206. [234]

Kahneman, Daniel and Amos Tversky (1979), "Prospect theory: An analysis of decision under risk." Econometrica, 47, 263-291. [224]

Kalwani, Manohar U. and Chi Kin Yim (1992), "Consumer price and promotion expectations: An experimental study.” Journal of Marketing Research, 29, 90-100. [234]

Karle, Heiko and Martin Peitz (2010), "Pricing and information disclosure in markets with loss-averse consumers.” Discussion Paper 312, Sonderforschungsbereich/ Transregio 15. [235]

Kashyap, Anil K. (1995), "Sticky prices: New evidence from retail catalogs." Quarterly Journal of Economics, 110, 245-274. [222]

Kehoe, Patrick J. and Virgiliu Midrigan (2008), “Temporary price changes and the real effects of monetary policy." Working Paper 661, Federal Reserve Bank of Minneapolis Research Department. [222, 236]

Klenow, Peter J. and Oleksiy Kryvtsov (2008), "State-dependent or time-dependent pricing: Does it matter for recent U.S. inflation?” Quarterly Journal of Economics, 123, 863-904. [222, 223]

Kőszegi, Botond (2010), “Utility from anticipation and personal equilibrium.” Economic Theory, 44, 415-444. [225, 228]

Kőszegi, Botond and Matthew Rabin (2006), "A model of reference-dependent preferences." Quarterly Journal of Economics, 121, 1133-1165. [217, 219, 223, 225, 234]

Kőszegi, Botond and Matthew Rabin (2009), "Reference-dependent consumption plans.” American Economic Review, 99, 909-936. [226, 228]

MacDonald, James M. and Daniel Aaronson (2006), "How firms construct price changes: Evidence from restaurant responses to increased minimum wages." American Journal of Agricultural Economics, 88, 292-307. [222, 223]

Macera, Rosario (2012), "Intertemporal incentives under loss aversion.” Unpublished paper. $[218,235]$

Nakamura, Emi and Jón Steinsson (2011), "Price setting in forward-looking customer markets.” Journal of Monetary Economics, 58, 220-233. [222, 236, 237]

Novemsky, Nathan and Daniel Kahneman (2005), "The boundaries of loss aversion." Journal of Marketing Research, 42, 119-128. [226]

Pesendorfer, Martin (2002), "Retail sales: A study of pricing behavior in supermarkets." Journal of Business, 75, 33-66. [235]

Rabin, Matthew (2000a), "Diminishing marginal utility of wealth cannot explain risk aversion." In Choices, Values, and Frames (Daniel Kahneman and Amos Tversky, eds.), 202-208, Cambridge University Press, Cambridge. [234] 
Rabin, Matthew (2000b), "Risk aversion and expected-utility theory: A calibration theorem.” Econometrica, 68, 1281-1292. [218]

Rabin, Matthew and Richard H. Thaler (2001), “Anomalies: Risk aversion.” Journal of Economic Perspectives, 15 (1), 219-232. [218, 234]

Rotemberg, Julio J. (2002), "Customer anger at price increases, time variation in the frequency of price changes and monetary policy.” Working Paper 9320, NBER. [237]

Rotemberg, Julio J. (2011), “Fair pricing." Journal of the European Economics Association, 9, 952-981. [237]

Shilony, Yuval (1977), "Mixed pricing in oligopoly." Journal of Economic Theory, 14, 373-388. [235]

Sibly, Hugh (2002), "Loss averse customers and price inflexibility." Journal of Economic Psychology, 23, 521-538. [218, 232, 235]

Slade, Margaret E. (1999), "Sticky prices in a dynamic oligopoly: An investigation of $(s, S)$ thresholds." International Journal of Industrial Organization, 17, 477-511. [236]

Smith, Alec (2008), "Lagged beliefs and reference-dependent utility." Unpublished paper, University of Arizona. [234]

Sobel, Joel (1984), “The timing of sales.” Review of Economic Studies, 51, 353-368. [235]

Sobel, Joel (1991), "Durable goods monopoly with entry of new consumers." Econometrica, 59, 1455-1485. [235]

Spiegler, Ran (2012a), "Consumer bounded rationality and rigidity/flexibility retail price patterns.” Economics Letters, 116, 335-338. [236]

Spiegler, Ran (2012b), “Optimal pricing under loss aversion: A 'cover version' of the Heidhues-Kőszegi-Rabin model.” Economic Theory, 51, 695-711. [235]

Sydnor, Justin (2010), “(Over)insuring modest risks.” American Economic Journal: Applied Economics, 2 (4), 177-199. [218]

Thaler, Richard (1980), “Toward a positive theory of consumer choice.” Journal of Economic Behavior and Organization, 1, 39-60. [220]

Tversky, Amos and Daniel Kahneman (1991), "Loss aversion in riskless choice: A reference-dependent model." Quarterly Journal of Economics, 106, 1039-1061. [224]

Varian, Hal R. (1980), “A model of sales.” American Economic Review, 70, 651-659. [235]

Winer, Russell S. (1986), "A reference price model of brand choice for frequently purchased products." Journal of Consumer Research, 13, 250-256. [234]

Zhou, Jidong (2011), "Reference dependence and market competition." Journal of Economics and Management Strategy, 20, 1073-1097. [235]

Submitted 2012-6-25. Final version accepted 2012-12-19. Available online 2013-1-1. 